IZA DP No. 6564

On the Organizational Structure of Multinational Firms: Which Sourcing Mode for Which Input?

Jens Südekum

Verena Nowak

Christian Schwarz

May 2012 


\title{
On the Organizational Structure of Multinational Firms: Which Sourcing Mode for Which Input?
}

\author{
Jens Südekum \\ University of Duisburg-Essen, \\ CESifo, IAB and IZA \\ Verena Nowak \\ University of Duisburg-Essen \\ Christian Schwarz \\ University of Duisburg-Essen
}

\author{
Discussion Paper No. 6564 \\ May 2012
}

\author{
IZA \\ P.O. Box 7240 \\ 53072 Bonn \\ Germany \\ Phone: +49-228-3894-0 \\ Fax: +49-228-3894-180 \\ E-mail: iza@iza.org
}

\begin{abstract}
Any opinions expressed here are those of the author(s) and not those of IZA. Research published in this series may include views on policy, but the institute itself takes no institutional policy positions.

The Institute for the Study of Labor (IZA) in Bonn is a local and virtual international research center and a place of communication between science, politics and business. IZA is an independent nonprofit organization supported by Deutsche Post Foundation. The center is associated with the University of Bonn and offers a stimulating research environment through its international network, workshops and conferences, data service, project support, research visits and doctoral program. IZA engages in (i) original and internationally competitive research in all fields of labor economics, (ii) development of policy concepts, and (iii) dissemination of research results and concepts to the interested public.
\end{abstract}

IZA Discussion Papers often represent preliminary work and are circulated to encourage discussion. Citation of such a paper should account for its provisional character. A revised version may be available directly from the author. 


\title{
ABSTRACT
}

\section{On the Organizational Structure of Multinational Firms: Which Sourcing Mode for Which Input?}

\begin{abstract}
Recent studies indicate that firms often outsource standard and simple tasks, while keeping complex and important inputs inside their boundaries. This observation is difficult to reconcile with the property rights approach of the firm, which suggests that important components should be outsourced in order to properly incentivize the respective suppliers. In this paper we introduce economies of scope into a property rights model where a producer contracts with two suppliers. The organizational decision is driven by two countervailing effects: the ownership rights effect favors outsourcing, while the "indirect" effect via the suppliers' costs favors vertical integration of both inputs. If production is highly component intensive, and if one input is much more important than the other, we show that vertical integration of the "more important" and outsourcing of the "less important" supplier is chosen in equilibrium. We also consider an open economy setup where the producer decides whether to offshore inputs.
\end{abstract}

\section{JEL Classification: D23, F12, L23}

Keywords: multinational firms, outsourcing, intra-firm trade, property rights approach

Corresponding author:

\author{
Jens Südekum \\ University of Duisburg-Essen \\ Mercator School of Management \\ Lotharstraße 65 \\ 47057 Duisburg \\ Germany \\ E-mail: jens.suedekum@uni-due.de
}




\section{Introduction}

Firms can choose different sourcing strategies for the intermediate inputs of their final products. Manufacturing components can either be produced in-house by subsidiaries that are vertically integrated within the firm's boundaries, or they may be subcontracted to external suppliers over which the firm has no direct control or ownership rights. This "make or buy" decision arises increasingly on a global scale. That is, firms may outsource not only domestically but also at arm's length in foreign countries. Similarly, they may obtain intermediates from domestic subsidiaries or from foreign affiliates via intra-firm trade.

One highly influential theory to understand firms' sourcing decisions is the property rights approach of the multinational enterprise (MNE). That approach has received considerable empirical support in the recent literature. In particular, studies by Nunn and Trefler (2008), Bernard et al. (2010), Federico (2010), Defever and Toubal (2011) or Corcos et al. (2012), among others, find that many predictions of the property rights model by Antràs and Helpman (2004) are consistent with firm-level evidence from various countries. For example, that model predicts that firms from more headquarter-intensive industries tend to engage less in outsourcing, which is in fact in line with the data.

Most recently, that empirical literature has started to emphasize that the characteristics of the inputs also matter for sourcing decisions. Alfaro and Charlton (2009) find that, within industries, firms tend to outsource mostly relatively low-skilled inputs from the early stages of the production process, while keeping high-skill inputs inside the firm's boundaries. Costinot et al. (2011) and Corcos et al. (2012) consistently find that intra-firm trade is more prevalent for non-routine activities and complex inputs while outsourcing is typically chosen for simpler and more standard tasks. To illustrate this point, consider the example of the three premium watchmakers Glashütte Original, Jaeger-LeCoultre and Rolex. All of them engage in some outsourcing: Glashütte obtains the dial and the watch hands from external suppliers, Jaeger-LeCoultre the glass and the leather for the bracelets, while Rolex subcontracts some material for the balance wheel. Those outsourced inputs are, of course, important and specific to the final design of the respective watch. Yet, the most complex components at the core of the final product, notably the clockworks, are produced in-house by all three firms. ${ }^{1}$

This empirical pattern is difficult to reconcile with the basic logic of the property rights approach. Within that theory, which relies crucially on incomplete contracts, a transfer of ownership rights raises a supplier's bargaining power and incentivizes him to invest into the relationship. On the one hand, this may explain why firms tend to outsource more in industries with a higher overall importance of manufacturing inputs for the production process - a pattern that is observed in the data. Yet, according to this logic one would also expect that firms within particular industries should mainly outsource their relatively most important components - a pattern that is not observed in the data.

\footnotetext{
${ }^{1}$ This conclusion, that firms often keep their most essential inputs vertically integrated, is in accordance with numerous studies from the business literature, where it is stressed that an internal organization of supplier relationships is particularly pervasive when dealing with complex products characterized by high interdependencies between various steps (see Bengtsson et al., 2009; Chesbrough and Teece, 1996; Lakemond et al., 2006; Ulrich and Ellison, 2005). For the particular example of the watchmakers, see Zeiteisen (2011a, b).
} 
To make sense of the empirical observation that firms often keep their relatively most important inputs vertically integrated, we introduce economies of scope into a property rights model of a multinational firm, more specifically, the model by Antràs and Helpman (2004). ${ }^{2}$ We formalize scope economies as extra unit costs of outsourcing which are either borne by the suppliers or by the firm. The assumption that unit costs are higher under an external than under an internal supplier organization is inspired by conceptual and empirical insights from other major theories of the firm, such as the transaction cost, the managerial incentives or the knowledge capital approach. In section 2 we briefly review several mechanisms, and argue that an internal supplier relationship can imply cost savings because of aspects such as easier communication, better knowledge and control inside the firm, fewer renegotiations over quality issues, lower probability for adaptions of specifically tailored inputs, and so on.

The baseline model by Antràs and Helpman (2004) has the limitation that it assumes a single component supplier whose organizational form is determined by the firm. While this setup is sufficient to analyze differences in sourcing patterns across industries, or across firms with varying productivity levels, it is not well suited for analyzing the central question of this paper ("which sourcing mode for which input?”). The reason is that the firm can essentially only choose to outsource or to integrate all inputs in that baseline model, whereas it is - by construction - not possible that the firm chooses a different sourcing mode for some suppliers than for others. We are, however, especially interested in such constellations where both sourcing modes co-exist within the same firm, because we can then analyze if firms tend to integrate or to outsource their relatively more important components. ${ }^{3}$

To study this question, we therefore develop an extension of the Antràs and Helpman-model with two imperfectly substitutable manufacturing components (each provided by a separate supplier) which can be asymmetric along various dimensions. ${ }^{4}$ A hold-up problem arises in our framework due to the assumed incompleteness of contracts, similarly as in the baseline model. Yet, the firm no longer encounters a bilateral bargaining with a single supplier, but a multilateral bargaining with two suppliers whose bargaining power depends on the distribution of ownership rights inside the firm. We use the Shapley value to study this more complex problem.

The producer's final organizational decision is driven by two countervailing effects in our model, which interact in shaping the overall value of the firm as well as the involved parties' investment incentives and bargaining powers. The "direct" effect captures the key mechanism of the property rights approach, the incentivizing impact of ownership rights. In addition, there is an "indirect" effect

\footnotetext{
${ }^{2}$ For a more general discussion of the property rights approach in an international trade context, see the recent surveys by Antràs (2012) and Antràs and Rossi-Hansberg (2009).

${ }^{3}$ Empirical evidence clearly shows that most firms actually choose such a "hybrid sourcing" pattern in which they have some external and some internal suppliers. See, for example, Kohler and Smolka (2012), Corcos et al. (2012), Defever and Toubal (2011), Jabbour and Kneller (2010), Jabbour (2008) or Tomiura (2007).

${ }^{4}$ In an important extension of the original Antràs and Helpman-framework, Du et al. (2009) consider a setup where the same input can be provided by two suppliers. "Bi-sourcing" (one supplier integrated and the other outsourced) can arise out of a strategic motive, because it systematically improves the headquarters' bargaining power. In our model the suppliers provide differentiated and asymmetric inputs, and we particularly focus on the question if the producer tends to integrate or to outsource the provider of the "more important" component.
} 
operating via the organization-specific unit costs. At first, we show that our model also predicts that higher headquarter-intensity lowers the firm's propensity to outsource. Yet, in contrast to the baseline model, our framework allows for the empirically highly relevant pattern of "hybrid sourcing" with one integrated and one outsourced component. Most importantly, if it were only for the direct effect, we show that the firm would never choose an organizational structure where the relatively "more important" component is integrated and the "less important" one is outsourced. The pure property rights approach (without economies of scope) thus fails to explain why many firms in practice actually choose such a sourcing pattern. This pattern can emerge, however, once the indirect effect is introduced. More specifically, if the overall component-intensity of production is high, and if the two inputs are sufficiently asymmetric, the firm chooses to integrate the more important input and to outsource the less important one. If this ownership pattern is implemented at home or abroad depends on the firm's productivity and on the level of offshoring costs.

\section{Extra costs of outsourcing - a review of the literature}

Apart from the property rights approach, there are at least three other major theoretical approaches that can be applied to the analysis of firms' organizational structures, and more specifically, to the question why firms choose particular sourcing modes for particular inputs:

- The transaction cost approach, which dates back to the seminal works by Coase (1937), Williamson (1975, 1985) and Dunning (1977).

- The managerial incentives approach with seminal contributions by Holmström and Milgrom (1991) and Aghion and Tirole (1997).

- $\quad$ The knowledge capital approach due to Ethier (1986) and Ethier and Markusen (1996).

The property rights model emphasizes the benefits of outsourcing, namely the incentivizing effect of ownership rights. Yet, within those other major theoretical approaches it has been repeatedly argued that outsourcing - or more generally, an external organization of supplier relationships - also induces costs. In this section we briefly review some of those arguments.

\section{Ex post negotiation and haggling}

Following Coase's (1937) seminal theory, Williamson $(1975,1985)$ distinguishes between ex ante and ex post transaction costs. From an ex ante perspective it is often claimed that outsourcing implies lower unit costs, e.g. because external suppliers can better specialize. However, there can be substantial ex post costs of outsourcing due to re-negotiation and haggling. According to Costinot et al. (2011), problems may arise during the production of complex intermediates. Given that not all eventualities can be specified ex ante, this then necessitates costly adaption of the inputs ex post. For integrated suppliers these adaption costs are substantially lower, because haggling can be reduced or avoided. Ex post transaction costs in the context of the "make or buy" decision are further discussed by Bajari and Tadelis (2001), Tadelis (2002) or Novak and Wernerfelt (2012). 


\section{Communication}

Cost advantages of an internal supplier organization may also arise, because communication channels within the firm are easier and more direct. According to Crémer et al. (2007), agents within a firm often use technical languages or specific "codes" to communicate with each other. For a standard contract that compromises all information, shared technical languages and codes are irrelevant. However, if difficulties arise during the production of a more complex input, such common language codes reduce the costs of problem solving. Empirical evidence in support of this channel is provided by $\mathrm{Li}$ (2009). He analyzes foreign sourcing decisions of MNEs in China, and finds that reductions in offshoring costs are associated with substantial increases of intra-firm trade in the most communication-intensive industries.

\section{Knowledge}

Higher outsourcing costs may also arise, because an internal organization facilitates the concentration of firm-specific knowledge. An early contribution emphasizing those aspects is Rugman (1986). In particular, Markusen (1995) and Ethier and Markusen (1996) argue that firms may fear a leakage of their "trade secrets" to external subcontractors, and would thus have to engage in costly measures to protect their firm-specific knowledge. Firms are thus reluctant to offshore their most important inputs, because the knowledge protection costs are then most severe. Recent work by Naghavi et al. (2011) finds support for this argument. They consider imitation risks associated with outsourcing, and find that French MNEs tend to keep highly knowledge-intensive inputs within their firm boundaries.

\section{Control and monitoring costs}

Costs for monitoring and control are typically lower for internal suppliers, since monitoring can be achieved more "economically" within the firm (Alchian and Demsetz, 1972). Several contributions emphasize that those higher control and monitoring costs have to be weighed against the benefits of outsourcing. According to Aghion and Tirole (1997), an outsourced agent may have more incentives to provide effort and to acquire relevant information. However, since the principal and the agent can have divergent interests, outsourcing also implies a costly loss of control. This trade-off is further studied in principal-agent models by Bental et al. (2012), Bae et al. (2010), Grossman and Helpman (2004) and Agrawal (2002). A similar approach focusing on the delegation of authority in corporate organizations is due to Marin and Verdier (2008, 2012).

\section{Quality}

Drawing on the control and monitoring channel just described, Lu et al. (2012) particularly identify lower quality as a potential cost of outsourcing. In their model, a component supplier's effort stochastically determines the quality of the manufacturing input and, thereby, the quality of the final product. The quality of the components is observable to the firm and to the supplier, but not verifiable 
by a court. When the supplier fails to deliver high-quality components, the court may make a mistake and fail to rule against the supplier. The authors show that product quality is lower under outsourcing compared to that under vertical integration in their model, particularly when contract enforcement becomes less effective. They test their model's predictions for a sample of firms producing in China, and find that a higher outsourcing share is associated with lower quality of the final product.

\section{Financial constraints}

Finally, financial constraints may also explain higher costs of outsourcing. Carluccio and Fally (2012) consider a setting with incomplete capital markets where suppliers are credit constrained. Since integrated suppliers are part of a multinational firm network, they are less affected than independent outsourced suppliers by those constraints to finance their initial input investments (also see Keuschnigg and Devereux, 2009). A higher technological complexity of an intermediate often requires more financial participation of the supplier, so that extra costs of outsourcing may be particularly relevant for those sophisticated inputs.

Summing up, all of these arguments may explain why an internal organization of suppliers via vertical integration may lead to unit cost advantages, as economies of scope can be exploited. ${ }^{5}$ Our theoretical framework introduces the notion of scope economies into a property rights approach of the firm. We formalize the extra costs of outsourcing in two different ways. In the baseline formulation, we assume that the suppliers' unit costs are higher as external subcontractors than as integrated affiliates, e.g. because of the financial channel or because they cannot easily access the firm's communication channels. In the Appendix we consider an alternative formalization and assume that the producer has to bear higher unit costs if she chooses an external supplier relationship, e.g. because of knowledge protection costs or due to a higher risk of ex post adaption if the supplier cannot be directly controlled or monitored.

\section{The model}

\subsection{Technology and demand}

We consider a firm that produces a final good $y$. Production of this good requires headquarter services and two different manufacturing components. The headquarter services are denoted by $h$ and are provided by the firm (the "producer") itself. The components are manufactured by suppliers. Specifically, we assume that there are two suppliers $a$ and $b$ who provide $m_{i}(i \in\{a, b\})$ units of their respective component.

\footnotetext{
${ }^{5}$ To be sure, even if outsourcing implies higher costs, there may be further reasons for this organizational choice from which we abstract in this paper. For example, Arya et al. (2008) analyze strategic incentives. In their model a final goods producer may choose to purchase inputs from an unrelated supplier, because that supplier would otherwise sell inputs to a direct competitor in the final goods market at favorable terms. Outsourcing is therefore chosen in that model, despite the fact that the input then has a higher price for the firm.
} 
The inputs are combined according to the following production function: ${ }^{6}$

$$
\begin{aligned}
& y=\theta \cdot\left(\frac{h}{\eta^{H}}\right)^{\eta^{H}} \cdot\left(\frac{M}{1-\eta^{H}}\right)^{1-\eta^{H}}, \text { where } \\
& M=\left[\eta_{a} \cdot\left(\frac{m_{a}}{\eta_{a}}\right)^{\varepsilon}+\eta_{b} \cdot\left(\frac{m_{b}}{\eta_{b}}\right)^{\varepsilon}\right]^{\frac{1}{\varepsilon}} .
\end{aligned}
$$

The upper tier production function (1) is a standard Cobb-Douglas, where $\theta$ denotes the firm's overall productivity level, $\eta^{H}$ is the headquarter-intensity, and $\eta^{M}=1-\eta^{H}$ is the overall componentintensity of the production process. The aggregate component input $M$ is given by a constant elasticity of substitution (CES) function as in (2), where $\eta_{i}$ denotes the input intensity of component $i$ within the aggregate $M$ (with $\eta_{a}+\eta_{b}=1$ ). The parameter $\varepsilon \in(0,1)$ measures how well the two components can be substituted. ${ }^{7}$

On the demand side, the firm faces an iso-elastic demand function for the final product,

$$
\text { (3) } y=Y \cdot p^{-\frac{1}{1-\alpha}}
$$

with $\alpha \in(0,1)$

where $p$ is the price, $Y>1$ is a demand shifter and $1 /(1-\alpha)>1$ is the demand elasticity. Combining (1)-(3) yields the firm's revenue which depends on the input levels $\left(h, m_{a}, m_{b}\right)$ :

$$
R=\theta^{\alpha} \cdot Y^{1-\alpha} \cdot\left[\left(\frac{h}{\eta^{H}}\right)^{\eta^{H}} \cdot\left(\frac{\left(\eta_{a} \cdot\left(\frac{m_{a}}{\eta_{a}}\right)^{\varepsilon}+\eta_{b} \cdot\left(\frac{m_{b}}{\eta_{b}}\right)^{\varepsilon}\right)^{1 / \varepsilon}}{1-\eta^{H}}\right)^{1-\eta^{H}}\right]^{\alpha}
$$

\subsection{The firm's organizational choice}

The producer's key decision in our model concerns the firm's organizational structure. This decision consists of two aspects, the "ownership" and the "global scale" choice. As for the former aspect, the producer decides for both components whether the respective supplier is an external subcontractor or a vertically integrated affiliate. Secondly, she decides on the global scale of the production process. Final assembly always takes place in the domestic country " $\mathrm{D}$ " where the producer itself is located. The input suppliers can be located either in $\mathrm{D}$, or in a foreign low-wage country $\mathrm{F}$. If supplier $i$ is located abroad, he then either collaborates via intra-firm trade (if he is vertically integrated) or via an arm's length relationship (foreign outsourcing). These organizational decisions are made in an environment with incomplete contracts à la Grossman and Hart (1986) and Hart and Moore (1990). All component and headquarter inputs are fully relationship-specific and non-contractible, as their

\footnotetext{
${ }^{6}$ This technology is similar as in Acemoglu et al. (2007) or Schwarz and Suedekum (2011), but assumes a discrete and fixed number of manufacturing components rather than a continuum of inputs.

${ }^{7}$ These technology parameters differ across firms and industries. The headquarter-intensity $\eta^{H}$ may, for example, be high in software or pharmaceutical firms and low, say, in firms from the motor vehicle industry. The parameter $\eta_{a}$ (with $\eta_{b}=1-\eta_{a}$ ) captures the degree of asymmetry of the two components. As an example, consider the production of Nespresso coffee capsules. This final good requires two highly specific components: the coffee, and the capsules. Here, substitutability is low, and the coffee tends to have the higher input intensity and generates more value added than the capsules per se. In software firms, inputs like code programming and technical support are more symmetric $\left(\eta_{a}\right.$ and $\eta_{b}$ are more similar) and better substitutable (higher $\varepsilon$ ).
} 
characteristics cannot be precisely specified ex ante, nor be verified by a third party (e.g., a court) ex post. ${ }^{8}$ Formally, we study the following five-stage game that we solve by backward induction:

1. The producer determines the organization of the firm by choosing simultaneously the ownership structure and the global scale of production. This decision is represented by a tuple $\Xi=\left\{\Xi_{a, r}, \Xi_{b, r}\right\}$, where $\Xi_{i, r}=O$ denotes outsourcing and $\Xi_{i, r}=V$ denotes vertical integration of the supplier of component $i \in\{a, b\}$ in country $r=\{D, F\}$.

2. Given this organizational decision, the firm offers contracts to potential suppliers. The contracts include an upfront participation fee $\tau_{i}$ (positive or negative) from supplier $i$.

3. There is a huge mass of potential suppliers for both components in both countries. Potential suppliers have an outside opportunity equal to $\mathrm{w}_{r}^{M}$ in country $r$. They apply for the contract, and the producer chooses one supplier for each component $i \in\{a, b\}$.

4. The headquarter and the suppliers $a$ and $b$ decide independently on their non-contractible input provision levels ( $h$ and, respectively, $m_{a}$ and $m_{b}$ ). The unit costs of headquarter services are given by $c^{H}$. The unit costs of production for input $i \in\{a, b\}$ depend on the producer's organizational decision and are given by $c_{i, r}+\rho_{i, r}^{\Xi_{i}}$ where $c_{i, r}$ are the raw production costs per unit. The term $\rho_{i, r}^{\Xi_{i}}$ is specific to the organizational form of supplier $i$, and we assume that $\rho_{i, r}^{O} \geq \rho_{i, r}^{V}$.

5. The three players bargain over the surplus value of the relationship. The final good is produced. Revenue is realized and distributed according to the outcome of the bargaining.

Some comments about this setup are necessary. Most importantly, notice that a hold-up problem arises due to the assumed contract incompleteness. Agents cannot commit on their input provision levels as stipulated in stages 2 and 3, so that the two suppliers and the producer end up in a bargaining over the surplus value of the relationship in stage 5 , at a time where all input provision costs are already sunk. Anticipating this, all parties tend to under-invest into their input provisions in stage 4.

The producer's ownership and global scale decisions from stage 1 matter, because they affect the bargaining powers of the involved parties and, hence, their incentives to contribute to the firm in stages 4 and 5. Consider first the ownership decision ("make or buy"). An outsourced supplier maintains the full property rights over his input, while a vertically integrated supplier is essentially an employee of the producer. An external supplier therefore tends to be in a better bargaining position vis-à-vis the producer, as he threatens to withhold his entire input level in stage 5. An integrated affiliate may also refuse to collaborate in the ultimate stage of the game. Yet, owing to her residual

\footnotetext{
${ }^{8}$ This contractual environment is surely an extreme one. It is assumed to stay as close as possible to the baseline model by Antràs and Helpman (2004). In an extension, Antràs and Helpman (2008) allow for partial contractibility of inputs and cross-country differences in contract enforcement. We could introduce these features into our model as well. This would, however, make the exposition considerably more complicated without affecting our main insights on the central question which sourcing mode is chosen for which type of input.
} 
control rights, it is then still possible for the producer to confiscate the supplier's input and to use it at least partly. This possibility, in turn, implies lower bargaining power of affiliates. This direct impact of the ownership decision on the suppliers' bargaining powers and incentives is a key element of the property rights approach to the firm. It is also an important mechanism in our framework.

In addition, we consider an indirect effect of the producer's ownership decision. Specifically, motivated by the evidence discussed in Section 2, we assume that vertical integration leads to lower unit costs of input provision than outsourcing. In the baseline formulation, we assume that by choosing the ownership structure the producer also pins down the suppliers' unit costs via the term $\rho_{i, r}^{\Xi_{i}}$. In the Appendix we consider a different formalization of scope economies and assume that the producer has to bear higher unit costs if she chooses an external supplier relationship. When making her final ownership decision in stage 1 , the producer takes into account both the direct effect operating via the assignment of property rights, and the indirect effect operating via the level of unit costs.

Finally, turning to the producer's global scale decision, this also affects the suppliers' unit costs. Here we assume that the raw production costs per unit of input, $c_{i, r}$, are lower in the foreign country, $c_{i, D}>c_{i, F}$, e.g., because suppliers have access to cheaper labor. We also allow the organizationspecific part of unit costs $\rho_{i, r}^{\Xi_{i}}$ to differ across countries in section 5.

\subsection{Solving the game}

Starting with stage 5, the surplus value over which the producer and the two suppliers bargain is the revenue level as given in (4). We denote the headquarter's revenue share by $\beta^{H}$ and the suppliers' shares by $\beta_{a}$ and $\beta_{b}$. Revenue is distributed such that $\beta^{H}+\beta_{a}+\beta_{b}=1$. For the modeling of the bargaining stage we use the Shapley value (see Shapley, 1953 or Acemoglu et al., 2007), which is a standard solution concept in multilateral bargaining contexts. The details are analyzed below.

In stage 4, agents choose their input provision levels, given the revenue shares that they anticipate to receive. The producer chooses $h$ so as to maximize $\beta^{H} \cdot R-c^{H} \cdot h$, and supplier $i \in\{a, b\}$ maximizes $\beta_{i} \cdot R-\left(c_{i, r}+\rho_{i, r}^{\Xi_{i}}\right) \cdot m_{i}$. It can be shown that the following input provision levels maximize the payoff of the producer and the suppliers, respectively:

$$
h=\frac{\alpha \cdot \eta^{H} \cdot \beta^{H}}{c^{H}} \cdot R \text { and } m_{i}=\alpha \cdot\left(1-\eta^{H}\right) \cdot \eta_{i} \cdot \frac{\left(\frac{\beta_{i}}{c_{i, r}+\rho_{i, r}^{\Xi_{i}}}\right)^{\frac{1}{1-\varepsilon}}}{\eta_{a} \cdot\left(\frac{\beta_{a}}{c_{a, r+\rho_{a, r}}}\right)^{\frac{\varepsilon}{1-\varepsilon}}+\eta_{b} \cdot\left(\frac{\beta_{b}}{c_{b, r}+\rho_{b, r}^{\Xi_{b}}}\right)^{\frac{\varepsilon}{1-\varepsilon}}} \cdot R
$$

with $\quad R=\Theta \cdot\left[\left(\frac{\beta^{H}}{c^{H}}\right)^{\eta^{H}} \cdot\left(\eta_{a} \cdot\left(\frac{\beta_{a}}{c_{a, r}+\rho_{a, r}^{\Xi}}\right)^{\frac{\varepsilon}{1-\varepsilon}}+\eta_{b} \cdot\left(\frac{\beta_{b}}{c_{b, r}+\rho_{b, r}^{\Xi_{b}}}\right)^{\frac{\varepsilon}{1-\varepsilon}}\right)^{\left(\frac{1-\varepsilon}{\varepsilon}\right) \cdot\left(1-\eta^{H}\right)}\right]^{\frac{\alpha}{1-\alpha}}$

where $\Theta \equiv Y \cdot(\alpha \cdot \theta)^{\frac{\alpha}{1-\alpha}}$ is an exogenous term capturing firm productivity and market size. 
As can be seen from (5), there is a trade-off between the revenue share and level: Everything else equal, a higher revenue share $\beta^{H}$ raises the headquarter's input provision $h$ and, hence, the revenue level. Yet, a higher $\beta^{H}$ lowers the remaining share $1-\beta^{H}=\beta_{a}+\beta_{b}$ for the suppliers, which in turn lowers their input provisions and, hence, the revenue level. This illustrates that the producer needs to properly incentivize the suppliers to tackle the underinvestment problem that is inherent in this game. Notice also that higher unit costs lead to a decrease of the input contribution of the respective agent. More specifically, $h$ from (5) is decreasing in $c^{H}$, ceteris paribus, while $m_{i}$ is decreasing in $\left(c_{i, r}+\rho_{i, r}^{\Xi_{i}}\right)$. Organizational decisions of the producer that affect the suppliers' unit costs therefore have an impact on their investment incentives and, in turn, on their bargaining powers. ${ }^{9}$

In stage 3, suppliers only apply for a contract if the overall payoff offered in stage 2 at least equals the outside option $\mathrm{w}_{r}^{M}$. A supplier's overall payoff is the anticipated revenue share and the participation fee, minus the costs of production. Thus, the participation constraint reads as $\beta_{i} \cdot R-\left(c_{i, r}+\rho_{i, r}^{\Xi_{i}}\right)$. $m_{i}+\tau_{i} \geq \mathrm{w}_{r}^{M}$. Since the producer can freely adjust the upfront payments in stage 2, those participation constraints will be satisfied with equality, i.e.:

$$
\beta_{i} \cdot R-\left(c_{i, r}+\rho_{i, r}^{\Xi_{i}}\right) \cdot m_{i}+\tau_{i}=\mathrm{w}_{r}^{M} \quad \Leftrightarrow \quad \tau_{i}=\mathrm{w}_{r}^{M}-\beta_{i} \cdot R+\left(c_{i, r}+\rho_{i, r}^{\Xi_{i}}\right) \cdot m_{i} .
$$

Finally, in the first stage the producer chooses the firm's organizational structure in order to maximize her own payoff. Due to the upfront participation fees (6), this implies that the producer's problem is equivalent to maximizing the joint payoff of all players:

$$
\pi=R-c^{H} \cdot h-\left(c_{a, r}+\rho_{a, r}^{\Xi_{a}}\right) \cdot m_{a}-\left(c_{b, r}+\rho_{b, r}^{\Xi_{b}}\right) \cdot m_{b}-w_{a}^{r}-w_{b}^{r}
$$

which can be rewritten as follows by using the expressions from (5):

$$
\begin{aligned}
& \pi=\Theta \cdot\left[\left(\frac{\beta^{H}}{c^{H}}\right)^{\eta^{H}} \cdot\left(\eta_{a} \cdot\left(\frac{\beta_{a}}{c_{a, r}+\rho_{a, r}^{\Xi a}}\right)^{\frac{\varepsilon}{1-\varepsilon}}+\eta_{b} \cdot\left(\frac{\beta_{b}}{c_{b, r}+\rho_{b, r}^{\Xi_{b}}}\right)^{\frac{\varepsilon}{1-\varepsilon}}\right)^{\left(\frac{1-\varepsilon}{\varepsilon}\right) \cdot\left(1-\eta^{H}\right)}\right]^{\frac{\alpha}{1-\alpha}} . \\
& {\left[1-\alpha \cdot\left(\eta^{H} \cdot \beta^{H}+\eta^{M} \cdot \frac{\eta_{a} \cdot\left(\frac{\beta_{a}}{c_{a, r}+\rho_{a, r}^{\Xi_{a}}}\right)^{\frac{1}{1-\varepsilon}}+\eta_{b} \cdot\left(\frac{\beta_{b}}{c_{b, r}+\rho_{b, r}^{\Xi_{b}}}\right)^{\frac{1}{1-\varepsilon}}}{\eta_{a} \cdot\left(\frac{\beta_{a}}{c_{a, r}+\rho_{a, r}^{\Xi_{a}}}\right)^{\frac{\varepsilon}{1-\varepsilon}}+\eta_{b} \cdot\left(\frac{\beta_{b}}{c_{b, r}+\rho_{b, r}^{\Xi_{b}}}\right)^{\frac{\varepsilon}{1-\varepsilon}}}\right)\right]-w_{a}^{r}-w_{b}^{r} .}
\end{aligned}
$$

The producer correctly anticipates the revenue shares $\beta^{H}, \beta_{a}$ and $\beta_{b}$ that are determined in the multilateral bargaining process in the ultimate stage of the game, to which we turn now.

\footnotetext{
${ }^{9}$ This would not be the case if the organizational choice only affected the firms' fixed costs but not the suppliers' unit costs.
} 


\subsection{The bargaining process}

The bargaining process is solved with the Shapley value approach. According to Acemoglu et al. (2007), a player's Shapley value is "the average of her contributions to all coalitions that consist of players ordered below her in all feasible permutations".

In our model, coalitions can contain one, two or three players. Zero output is produced and no revenue is generated by coalitions consisting only of a single player, or by coalitions of the two suppliers. These coalitions are not feasible. Only coalitions consisting of the producer and at least one input supplier are feasible. Within the set of feasible coalitions, the players can be ordered in different ways and those different orderings are called permutations. For each of these orderings the respective last player's marginal contribution is determined, i.e., the difference between the revenue of the coalition when the respective player is part of it, and the coalition's revenue when the respective player is not part of it. Consider first the marginal contribution of the producer. As headquarter services are the only essential input, the producer's marginal contribution always equals the total revenue of the respective coalition as revenue would drop to zero if she were to leave the coalition. This is true both for the coalition of size three (consisting of the producer and both suppliers), and for the two feasible coalitions of size two (consisting of the producer and one supplier $i \in\{a, b\}$ ).

For the suppliers, their marginal contributions depend on the ownership structure of the firm. During the bargaining, when supplier $i$ refuses to collaborate, he threatens to withhold the fraction $\delta_{i}^{\Xi_{i}}$ of his input while the producer can keep and effectively use the fraction $\left(1-\delta_{i}^{\Xi_{i}}\right)$. If supplier $i$ is outsourced, we have $\delta_{i}^{O}=1$ since external suppliers maintain their full property rights and thus threaten to withhold their entire input. When supplier $i$ is integrated, the producer can use the fraction $0<\left(1-\delta_{i}^{V}\right)<1$ of the input. The fraction $\delta_{i}^{V}$ is lost, because the internal suppliers have specific knowledge about the usability of the component. The lower $\delta_{i}^{V}$ is, the easier it is for the producer to use the component even without the collaboration of the supplier, and the more significant is the difference between outsourcing and integration for the supplier's bargaining power. The parameter $\delta_{i}^{\mathrm{V}}$ thus captures the direct effect of the ownership choice on the suppliers' bargaining power. The producer's marginal contribution to a coalition of size two (denoted as $M C_{H i}^{2}$ ), which is equivalent to the total revenue of that coalition, can be formally expressed as

$$
M C_{H i}^{2}=\widehat{H} \cdot m_{i}^{\alpha \cdot\left(1-\eta^{H}\right)} \eta_{i}^{\frac{\alpha \cdot(1-\varepsilon) \cdot\left(1-\eta^{H}\right)}{\varepsilon}}
$$

with $\widehat{H}=\theta^{\alpha} \cdot Y^{1-\alpha} \cdot h^{\alpha \cdot \eta^{H}} \cdot\left(1-\eta^{H}\right)^{-\alpha \cdot\left(1-\eta^{H}\right)} \cdot\left(\eta^{H}\right)^{-\alpha \cdot \eta^{H}}$, where $i \in\{a, b\}$ indexes the supplier with whom the headquarter has formed the coalition. For the coalition of size three, the producer's marginal contribution is given by

$$
M C_{H}^{3}=\widehat{\mathrm{H}} \cdot\left(m_{i}^{\varepsilon} \cdot \eta_{i}^{1-\varepsilon}+m_{j}^{\varepsilon} \cdot \eta_{j}^{1-\varepsilon}\right)^{\frac{\alpha \cdot\left(1-\eta^{\mathrm{H}}\right)}{\varepsilon}} .
$$


For an outsourced supplier, his contribution to a coalition of size two (denoted as $M C_{i}^{2^{O}}$ ) also equals the total revenue of that coalition, hence $M C_{i}^{2}{ }^{O}=M C_{H i}^{2}$ as given in (9). When supplier $i$ is integrated, total revenue does not fall to zero if he leaves the coalition. The producer can then keep the part $\left(1-\delta_{i}^{V}\right)$ of that supplier's input, and the remaining coalition (of size one) earns $\widehat{H} \cdot\left(\left(1-\delta_{i}^{V}\right) \cdot m_{i}\right)^{\alpha \cdot\left(1-\eta^{H}\right)} \cdot \eta_{i}^{\alpha \cdot(1-\varepsilon) \cdot\left(1-\eta^{H}\right) / \varepsilon}$. Therefore, the marginal contribution of a vertically integrated supplier to a coalition of size two is given by

$$
M C_{i}^{2^{V}}=\widehat{H} \cdot\left(m_{i}^{\alpha \cdot\left(1-\eta^{H}\right)} \cdot \eta_{i}^{\frac{\alpha \cdot(1-\varepsilon) \cdot\left(1-\eta^{H}\right)}{\varepsilon}}-\left(\left(1-\delta_{i}^{V}\right) \cdot m_{i}\right)^{\alpha \cdot\left(1-\eta^{H}\right)} \cdot \eta_{i}^{\frac{\alpha \cdot(1-\varepsilon) \cdot\left(1-\eta^{H}\right)}{\varepsilon}}\right)
$$

Finally, a supplier's marginal contribution to the coalition of size three can be written as

$$
\mathrm{MC}_{\mathrm{i}}^{3}=\hat{H} \cdot\left(\left(m_{i}^{\varepsilon} \cdot \eta_{i}^{1-\varepsilon}+m_{j}^{\varepsilon} \cdot \eta_{j}^{1-\varepsilon}\right)^{\frac{\alpha \cdot\left(1-\eta^{H}\right)}{\varepsilon}}-\left(\left(\left(1-\delta_{i}^{\Xi_{i}}\right) \cdot m_{i}\right)^{\varepsilon} \cdot \eta_{i}^{1-\varepsilon}+m_{j}^{\varepsilon} \cdot \eta_{j}^{1-\varepsilon}\right)^{\frac{\alpha \cdot\left(1-\eta^{H}\right)}{\varepsilon}}\right)
$$

with $\mathrm{i} \neq \mathrm{j}$ and $\delta_{\mathrm{i}}^{\mathrm{O}}=1,0<\delta_{\mathrm{i}}^{\mathrm{V}}<1$. Using these marginal contributions, the players' Shapley values are calculated according to

$$
S V_{k}=\sum_{S \subseteq N} \frac{(s-1) ! \cdot(n-s) !}{n !} M C_{k}^{S} \text { for } k \in\{H, a, b\},
$$

where $n$ is the total number of players, and $s$ the number of players in a coalition $(s \leq n)$. The term $(s-1) ! \cdot(n-s) ! / n$ ! thus captures the weights when forming the average across all feasible permutations, and it equals the probability that a specific player $k$ is in the last position of such a permutation. In our specific context, we have $n=3$ so that this probability is equal to $1 / 3$ for the coalition with three players, and 1/6 for a coalition of two players. Using (13) and the marginal contributions (9) - (12), the Shapley value of supplier $i$ is thus

$$
S V_{i}=\frac{1}{6} \cdot M C_{i}^{2}+\frac{1}{3} \cdot M C_{i}^{3}
$$

Analogously, the Shapley value of the producer is

$$
S V_{H}=\frac{1}{6} \cdot M C_{H i}^{2}+\frac{1}{6} \cdot M C_{H j}^{2}+\frac{1}{3} \cdot M C_{H}^{3} \quad \text { with } \mathrm{i} \neq \mathrm{j} \text {. }
$$

These Shapley values form the basis for the determination of the revenue distribution. Namely, the revenue share of supplier $i \in\{a, b\}$ is given by his Shapley value divided by the firm's total revenue:

(16) $\quad \beta_{i}=\frac{S V_{i}}{R}=$

$$
\frac{m_{i}^{\alpha \cdot\left(1-\eta^{\mathrm{H}}\right)} \cdot \eta_{i}^{\alpha \cdot(1-\varepsilon) \cdot\left(1-\eta^{\mathrm{H}}\right) / \varepsilon}+2\left(\left(m_{i}^{\varepsilon} \cdot \eta_{i}^{1-\varepsilon}+m_{j}^{\varepsilon} \cdot \eta_{j}^{1-\varepsilon}\right)^{\alpha \cdot\left(1-\eta^{\mathrm{H}}\right) / \varepsilon}-\left(\left(\left(1-\delta_{i}^{\Xi_{i}}\right) \cdot m_{i}\right)^{\varepsilon} \cdot \eta_{i}^{1-\varepsilon}+m_{j}^{\varepsilon} \cdot \eta_{j}^{1-\varepsilon}\right)^{\alpha \cdot\left(1-\eta^{\mathrm{H}}\right) / \varepsilon}\right)}{6 \cdot\left(m_{a}^{\varepsilon} \cdot \eta_{a}^{1-\varepsilon}+m_{b}^{\varepsilon} \cdot \eta_{b}^{1-\varepsilon}\right)^{\alpha \cdot\left(1-\eta^{\mathrm{H}}\right) / \varepsilon}} .
$$


The headquarter's revenue share is then determined as the residual, i.e., it is given by $\beta^{H}=1-\beta_{a}-\beta_{b}$, where $\beta_{a}$ and $\beta_{b}$ follow from (16). ${ }^{10}$ Notice that these revenue shares $\beta_{a}$ and $\beta_{b}$ are functions of the input provision levels $m_{a}$ and $m_{b}$, which in turn depend on the revenue shares, see equation (5). As a result, we cannot solve analytically but only numerically for the Shapley values and the revenue shares of the suppliers and the producer.

\section{Closed economy}

Ultimately, our aim is to analyze which organization (ownership and global scale) the producer chooses for different technology parameters that characterize the firm's production process. To facilitate this analysis, we abstract from the global scale dimension for the moment and start with a closed economy setup where both suppliers are located in the domestic country D. In section 4.1 we first examine the bargaining stage of the game, before turning to the payoff-maximizing ownership choice in section 4.2 .

\subsection{Shapley values and revenue shares in the multilateral bargaining}

In this subsection, we proceed in three steps. First, we illustrate how the basic technology parameters (input intensities and raw unit costs) affect the Shapley values of the three players and thereby the firm's revenue distribution. Here we still abstract from the direct and indirect impacts of the ownership decision by setting $\delta_{i}^{O}=\delta_{i}^{V}=1$ and $\rho^{O}=\rho^{V}=0$. Second, we consider the direct impact of the ownership decision by taking into account that outsourcing and integration imply different property rights for the suppliers $\left(0<\delta_{i}^{V}<\delta_{i}^{O}=1\right)$. Finally, we introduce the indirect impact by allowing the unit costs of supplier $i$ to also depend on his organizational form, i.e., by assuming that $\rho^{O}>\rho^{V}$.

\section{a) Technological parameters: input intensities and unit costs}

The first important technology parameter that affects the revenue distribution inside the firm is the headquarter-intensity of final goods production. To isolate the impact of $\eta^{H}$ it is useful to first consider a benchmark scenario where the two components are symmetric in terms of their input intensities $\left(\eta_{a}=\eta_{b}=1 / 2\right)$ and raw unit costs $\left(c_{a}=c_{b}\right)$. Figure 1a illustrates how the revenue distribution changes with $\eta^{H}$. The left panel refers to the revenue share (Shapley value over total revenue) of supplier $a$ which by symmetry is identical to supplier $b$ 's revenue share. The right panel depicts the residual share $\beta^{H}$. As can be seen, the higher is $\eta^{H}$ the lower is the revenue share of both suppliers and the higher is the producer's residual revenue share. The reason is simple: The higher is $\eta^{H}$, the lower

\footnotetext{
${ }^{10}$ The sum of the marginal contributions of all suppliers must equal the total revenue. However, the allocation of the marginal contributions is not necessarily efficient: the sum of the marginal contributions may deviate from the revenue of the coalition (see Hart, 1990; Hart and Mas-Colell, 1988). To assure that the total revenue is distributed among the three players, the revenue shares are thus only calculated for two players, namely the two suppliers. One player receives the residual revenue share, as in Hart and Moore (1990). The producer is this residual claimant, since she is the only essential player in this bargaining game.
} 
is the overall technological importance of the components for the production process. Both suppliers thus make lower marginal contributions to all relevant coalitions, and thus have lower Shapley values as they threaten to take away less important inputs. This lower bargaining power, in turn, implies a higher residual revenue share for the producer. ${ }^{11}$
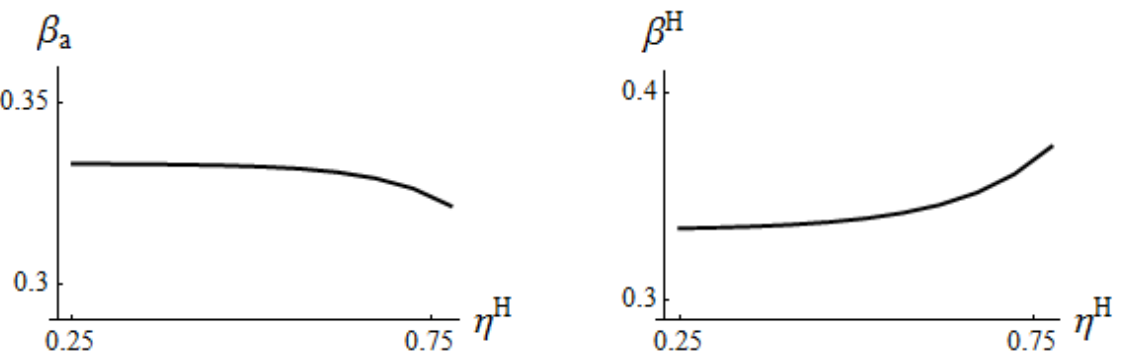

Figure 1a: Variation of the headquarter-intensity $\eta^{\mathrm{H}}$

$$
\left(\eta_{\mathrm{a}}=\eta_{\mathrm{b}}=0.5, \mathrm{c}_{\mathrm{a}}=\mathrm{c}_{\mathrm{b}}=1, \mathrm{c}^{\mathrm{H}}=1, \delta^{\mathrm{O}}=\delta^{\mathrm{V}}=1, \rho^{\mathrm{O}}=\rho^{V}=0, \varepsilon=0.06, \alpha=0.92, \theta=1, Y=1\right) .
$$

Now suppose that the two components are asymmetric in terms of their technological importance, i.e., their input intensities. In figure $1 \mathrm{~b}$ we depict the revenue shares of suppliers $a$ and $b\left(\beta_{a}\right.$ and $\beta_{b}$ ) as a function of $\eta_{a}$, now for a given value $\eta^{H}=0.3$ and for unchanged values of the other parameters. The figure shows that the supplier who provides the more important input realizes the higher revenue share. In particular, the share $\beta_{a}$ is increasing in $\eta_{a}$, while $\beta_{b}$ is decreasing in $\eta_{a}$ since $\eta_{b}=1-\eta_{a}$. Clearly, with $\eta_{a}>1 / 2$ supplier $a$ has a higher Shapley value than supplier $b$. Put differently, supplier $a$ has a higher bargaining power as he threatens to withhold the more important component.

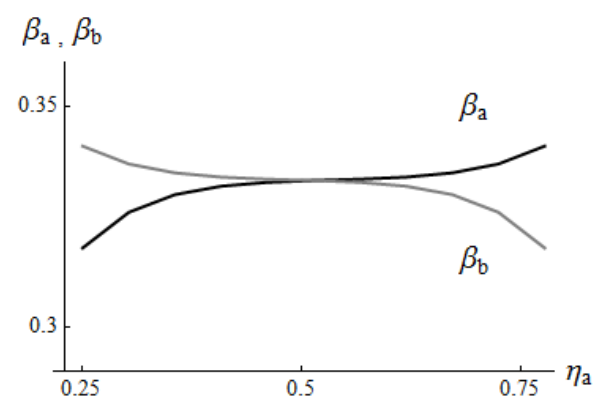

Figure 1b: Technological asymmetry across components $\left(\eta^{H}=0.3, c_{a}=c_{b}=1, c^{H}=1, \delta^{0}=\delta^{V}=1, \rho^{0}=\rho^{V}=0, \varepsilon=0.06, \alpha=0.92, \theta=1, Y=1\right)$.

Finally, consider the impact of the raw unit costs. Starting from figure 1a, we first consider a simultaneous unit cost increase for both symmetrical components (e.g., $c_{a}=c_{b}=c>1$ ). It is clear from equation (5) that this cost increase leads to lower input provisions of both suppliers, and thus to a lower revenue level for the firm. However, it turns out that the revenue distribution is unaffected, i.e.,

\footnotetext{
${ }^{11}$ This bargaining outcome is thus consistent with efficiency considerations from contract theory. All parties under-invest into the relationship due to the hold-up problem. The higher (lower) is $\eta^{H}$, the slacker (fiercer) are the suppliers' underinvestment problems. Hence, to ensure ex ante efficiency it becomes less (more) important to incentivize the suppliers, and hence they should receive a smaller (larger) share of the surplus.
} 
the revenue shares $\beta_{a}=\beta_{b}$ (and thus, $\beta^{H}$ ) remain unchanged when $c$ increases. This would also be the case if we additionally assumed a technological asymmetry as in figure 1b. That figure is constructed for identical raw unit costs $\mathrm{c}_{\mathrm{a}}=\mathrm{c}_{\mathrm{b}}=1$, but it would look identical for a higher common unit cost level $c_{a}=c_{b}=c>1$.

The revenue distribution is affected, however, once there is a cost asymmetry across the two suppliers. Figure 1c is analogous to figure 1a and depicts $\beta_{a}$ (left panel) and $\beta^{H}$ (right panel) as a function of $\eta^{H}$. The black lines in both panels refer to the benchmark case with identical unit costs, while the grey lines refer to the case where unit costs $c_{a}$ are higher than $c_{b}$. As the left graph shows, the higher unit costs $c_{a}$ reduce supplier $a$ 's revenue share $\beta_{a}$. The other supplier and the producer, on the other hand, end up with higher revenue shares for any given level of $\eta^{H}$. For $\beta^{H}$, this can be seen in the right panel of figure 1c where the grey line always runs above the black one. That is, a unit cost rise of one supplier (with constant unit costs of the other supplier) actually leads to a higher realized revenue share for the producer, because supplier $a$ experiences a strong loss in his bargaining power.
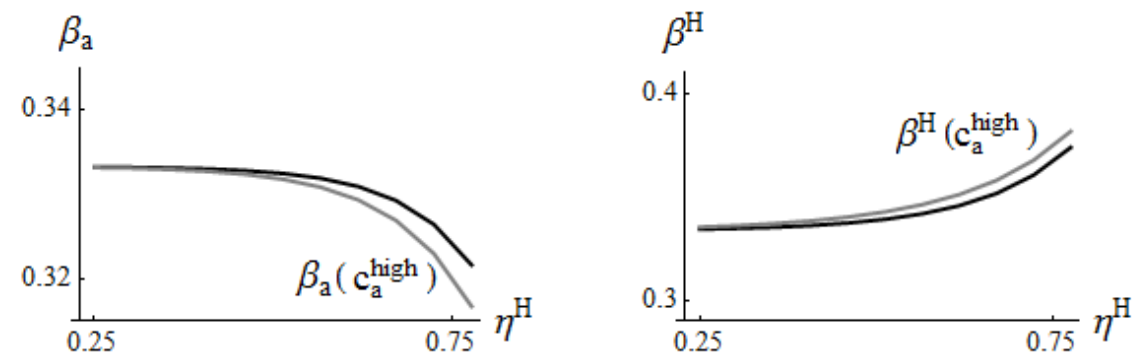

Figure 1c: Asymmetries in suppliers' unit costs

(black lines: $c_{a}=c_{b}=1$; grey lines: $c_{a}=3, c_{b}=1$. Other parameters as in figure 1a.).

\section{b) Direct impact of the ownership decision: Property rights of the supplier}

We now study the direct impact of the producer's ownership decision on the Shapley values by assuming that $0<\delta^{V}<1$ while $\delta^{O}=1$. We do, however, not yet consider the indirect impact but for the moment continue to assume that $\rho^{O}=\rho^{V}=0$.

In the left panel of figure 2 we depict the revenue share of supplier $a$ as a function of the input intensity $\eta_{a}$ for the four different ownership structures that can emerge in our model. ${ }^{12}$ For any given $\eta_{a}$, the revenue share of supplier $a$ is higher if he is outsourced than if he is vertically integrated. More specifically, the $\beta_{a}^{\{O, O\}}$ curve runs above the $\beta_{a}^{\{V, O\}}$ curve, and the $\beta_{a}^{\{O, V\}}$ curve runs above the $\beta_{a}^{\{V, V\}}$ curve. The reason is that supplier $a$ makes higher marginal contributions to all feasible permutations (for a given $\eta_{a}$ ) owing to the fact that he maintains the property rights and, thus, has a higher Shapley value if he is outsourced than if he is integrated. However, the revenue share of supplier $a$ not only depends on his own organizational form, but also on the organization of the other supplier. In

\footnotetext{
${ }^{12}$ We assume a fixed value for the headquarter-intensity $\eta^{H}$, and we assume that the two suppliers have identical raw unit costs. Changes in those parameters would have qualitatively similar effects as illustrated above.
} 
particular supplier $a$ receives a higher revenue share when supplier $b$ is integrated than if supplier $b$ is outsourced, $\beta_{a}^{\{O, V\}}>\beta_{a}^{\{O, O\}}$ and $\beta_{a}^{\{V, V\}}>\beta_{a}^{\{V, O\}}$ for any given $\eta_{a}$. The intuition is that the producer can always rely on the fact that she would retain a part of input $b$ when supplier $b$ is vertically integrated. Since the two components are substitutes, the bargaining power of supplier $a$ therefore increases compared to the constellation where supplier $b$ threatens to withhold his entire input level.
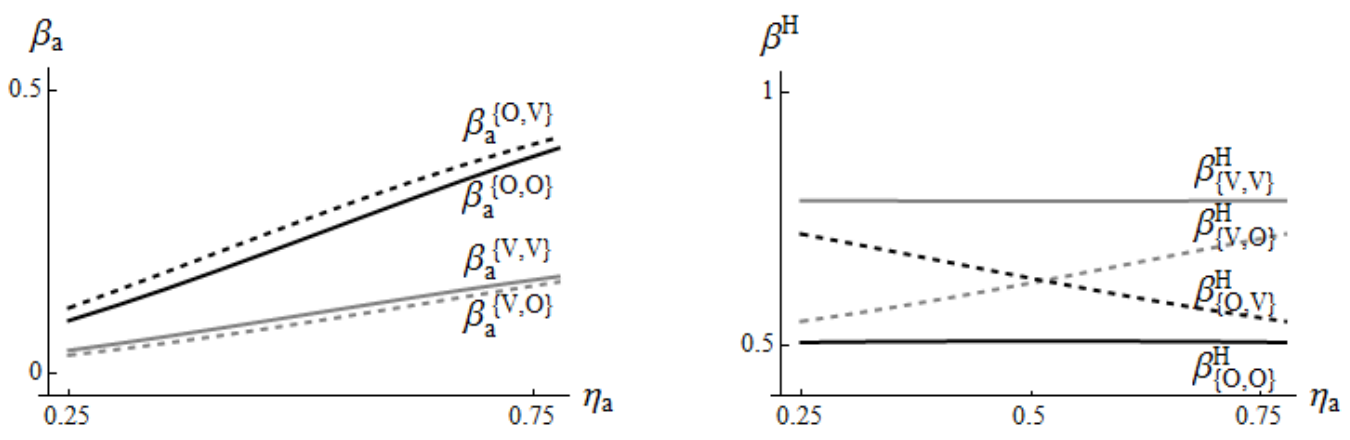

Figure 2: Outsourcing versus integration: The revenue shares $\left(\eta^{H}=0.8, c_{a}=c_{b}=1, c^{H}=1, \delta^{0}=1, \delta^{\mathrm{V}}=0.95, \rho^{\mathrm{O}}=\rho^{\mathrm{V}}=0, \varepsilon=0.2, \alpha=0.92, \theta=1, Y=1\right)$.

The right panel of figure 2 illustrates the headquarter revenue share for the four different ownership structures. This revenue share is the highest when both suppliers are integrated $\left(\beta_{\{V, V\}}^{H}\right)$, because both suppliers then have low bargaining powers due to the lack of property rights. Vice versa, $\beta^{H}$ is the lowest when both suppliers are outsourced $\left(\beta_{\{0, O\}}^{H}\right)$. For the intermediate cases with one integrated and one outsourced supplier, the headquarter revenue share ranges in between $\beta_{\{O, O\}}^{H}$ and $\beta_{\{V, V\}}^{H}$. In those cases, that we shall refer to as "hybrid sourcing", the headquarter share is lower when the more important supplier is outsourced, i.e., $\beta_{\{O, V\}}^{H}<\beta_{\{V, O\}}^{H}$ for $\eta_{a}>1 / 2$, and vice versa for $\eta_{a}<1 / 2$.

\section{c) Indirect impact of the ownership decision: Higher unit costs of external suppliers}

Finally, we jointly consider the direct and the indirect impact of the producer's ownership decision by assuming that $\rho^{O}>0$ while $\rho^{V}=0$. That is, each supplier $i$ now has higher total unit costs if he is outsourced than if he is vertically integrated. To illustrate the impact on the revenue distribution, assume a fixed headquarter-intensity and suppose that the two components are symmetric in terms of input intensities and raw unit costs. Figure 3 depicts the resulting revenue share of supplier $i \in\{a, b\}$ as a function of the extra unit costs of outsourcing, $\rho^{O}$.

Provided that both suppliers have the same organizational form, these additional costs do not affect the suppliers' revenue shares. With the ownership choice $\{V, V\}$ these costs are immaterial, since no supplier is actually outsourced. With $\{O, O\}$ there is an increase in the total unit cost level for both suppliers as $\rho^{O}$ increases, but no effective cost asymmetry across suppliers. As argued before, this common cost increase lowers the firm's revenue level but it does not change the revenue distribution. Consequently there is no effect of $\rho^{O}$ on $\beta_{a}^{\{O, O\}}$ and $\beta_{b}^{\{O, O\}}$ and, hence, no effect on $\beta_{\{O, O\}}^{H}$. 


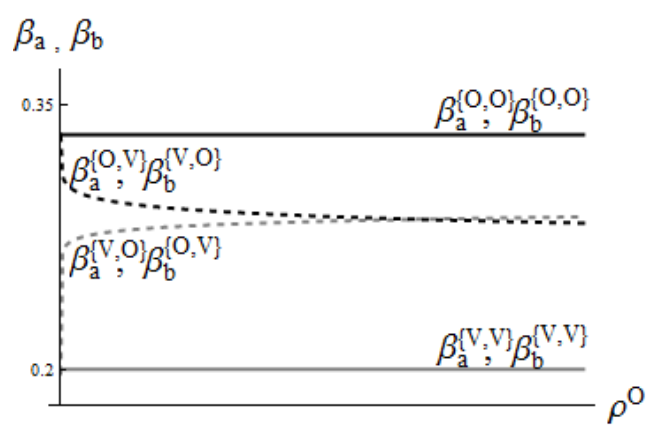

Figure 3: Revenue share of supplier $a$ subject to a variation of scope economies $\rho^{O}$ $\left(\eta^{H}=0.3, \eta_{a}=\eta_{b}=0.5, c_{\mathrm{a}}=c_{\mathrm{b}}=1, \mathrm{c}^{\mathrm{H}}=1, \delta^{\mathrm{O}}=1, \delta^{\mathrm{V}}=0.95, \rho^{\mathrm{V}}=0, \varepsilon=0.06, \alpha=0.92, \theta=1, Y=1\right)$.

The impact of the extra unit costs of outsourcing becomes visible in the cases of "hybrid sourcing" where one supplier is integrated and the other is outsourced. As can be seen in figure 3 , when $\rho^{O}$ is small, we have $\beta_{a}^{\{O, V\}}>\beta_{a}^{\{V, O\}}$ and analogously $\beta_{b}^{\{V, O\}}>\beta_{b}^{\{O, V\}}$. In other words, given that the ownership form differs across the two suppliers, we find that supplier $i$ has a higher bargaining power if he is the external and the other supplier $j$ is the internal one. The reason is that supplier $i$ then maintains the property rights over his input, whereas the induced cost disadvantage from being outsourced is still small. However, once the extra costs of outsourcing $\rho^{O}$ have become sufficiently large, we find that $\beta_{a}^{\{O, V\}}<\beta_{a}^{\{V, O\}}$ and analogously that $\beta_{b}^{\{V, O\}}<\beta_{b}^{\{O, V\}}$. In other words, for the cases of hybrid sourcing we now find that the revenue share of supplier $i$ is higher if he is the vertically integrated affiliate and the other supplier $j$ is the external subcontractor. The reason is that the external supplier $j$ now faces a huge cost disadvantage compared to the affiliate $i$, and this effect more than offsets the disadvantage that supplier $i$ has lost the property rights over his input.

\subsection{Payoff-maximizing ownership form}

We now turn to the headquarters' final ownership choice. The producer chooses the tuple $\Xi=$ $\left\{\Xi_{a}, \Xi_{b}\right\}$, with $\Xi_{i} \in\{O, V\}$, taking into account the firm's technology parameters and anticipating the implications of her decision for the revenue distribution.

\section{a) Benchmark case: Only direct impact of the ownership decision}

Assume at first that $\rho^{O}=0$, i.e., we shut down the indirect impact of the ownership decision and assume that the unit costs are not organization-specific. The producer's decision for this case is depicted in the left panel of figure 4. We display the headquarter-intensity $\eta^{H}$ on the horizontal axis and the degree of the technological asymmetry $\eta_{a}$ on the vertical axis (with $\eta_{a}=1 / 2$ being the benchmark with symmetric components). The different colors specify which ownership decision is payoff-maximizing for the firm.

When the headquarter-intensity $\eta^{H}$ is sufficiently low, the producer decides to outsource both suppliers (blue color). Low headquarter-intensity implies that components are very important in the 
production process overall $\left(1-\eta^{H}\right.$ is high). Since the supplier's bargaining powers and incentives are higher for outsourcing than for integration according to the direct property rights channel, it is optimal for the producer to transfer ownership rights to the suppliers by choosing outsourcing. Analogously, if $\eta^{H}$ is sufficiently high, the producer chooses to keep both suppliers vertically integrated (red color). Although the investment incentives of the suppliers are worse in that case, this is of lesser significance since components are not so important for the production process. The producer, on the other hand, provides a highly important input, and by choosing complete vertical integration, she can assign a high residual revenue share to herself to tackle her own underinvestment problem. Notice that these results are qualitatively similar to those of the baseline model by Antràs and Helpman (2004), and therefore in line with numerous empirical studies that found support for these predictions.
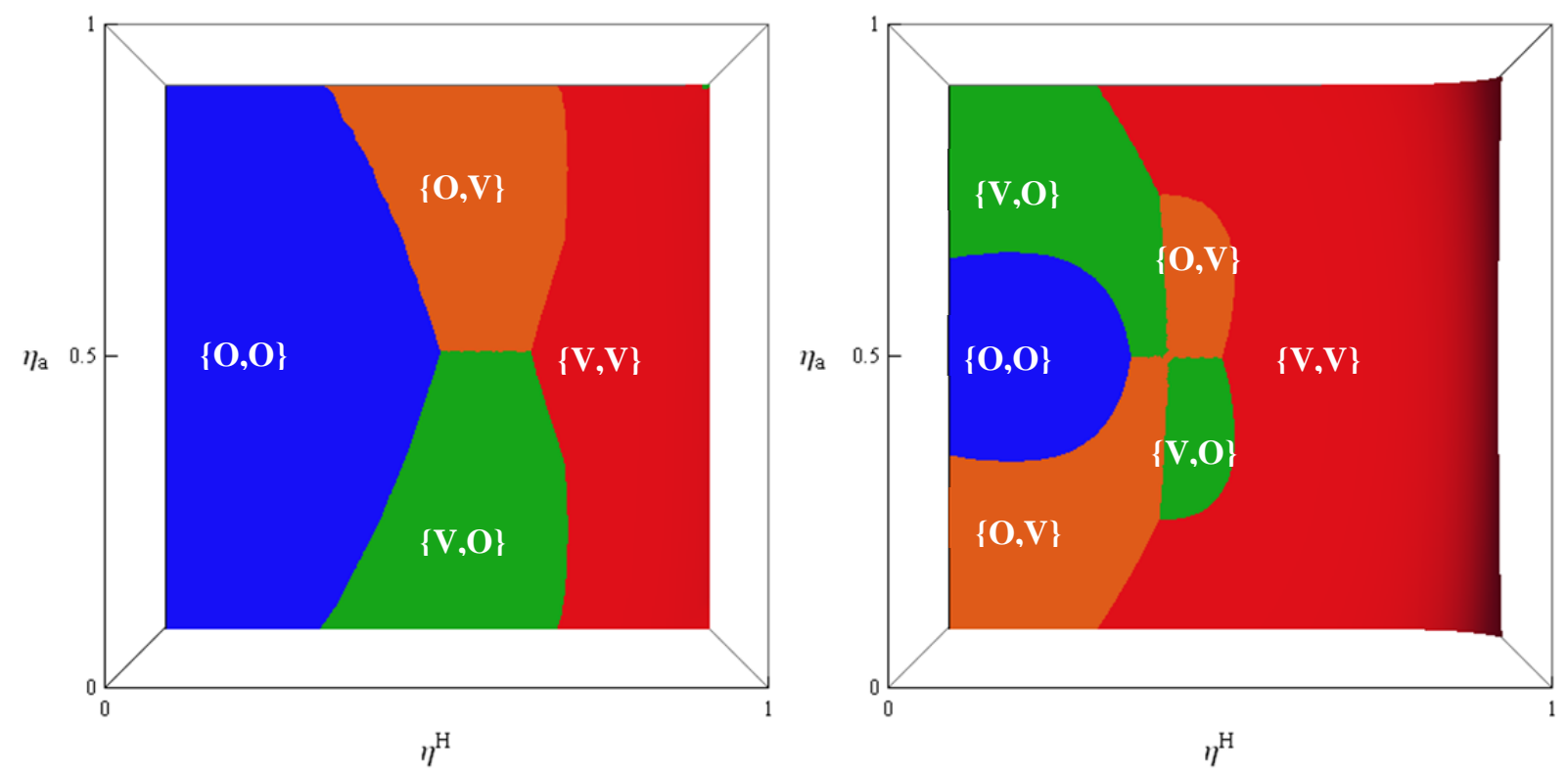

Figure 4: Ownership decision in the closed economy, without and with economies of scope

$$
\begin{array}{cc}
\text { left panel: } \rho^{O}=0 & \text { right panel: } \rho^{O}=0.2 \\
\left(\mathrm{c}_{\mathrm{a}}=\mathrm{c}_{\mathrm{b}}=1, \mathrm{c}^{\mathrm{H}}=1, \delta^{\mathrm{O}}=1, \delta^{\mathrm{V}}=0.95, \rho^{V}=0, \varepsilon=0.06, \alpha=0.92, \theta=1, Y=1\right) .
\end{array}
$$

Importantly, for intermediate values of the headquarter-intensity $\eta^{H}$ we find that the producer chooses to outsource one supplier while vertically integrating the other. As argued before, such a co-existence of both organizational forms within the same firm ("hybrid sourcing") is an empirically highly relevant phenomenon, and by construction it cannot occur in the baseline model by Antràs and Helpman (2004) with just one single supplier / component, while it can occur in our framework with multiple (i.e., at least two) suppliers.

When does hybrid sourcing occur, and if it occurs, which organizational mode is chosen for which component? The left panel of figure 4 shows that the technological asymmetry across the two components makes the occurrence of hybrid sourcing overall more likely. This can be seen by noting that the parameter range of $\eta^{H}$ where hybrid sourcing is chosen expands the further away $\eta_{a}$ is from the benchmark value of $1 / 2$. Furthermore, when only the direct impact of the ownership decision matters, it follows for the cases of "hybrid sourcing" that the producer would always outsource the 
supplier with the technologically more important component. This can be seen by noting that whenever input $a$ is the more important one ( $\left.\eta_{a}>1 / 2\right)$, only the organizational form $\{O, V\}$ prevails (orange) but never the form $\{V, O\}$. Vice versa, for $\eta_{a}<1 / 2$ we only observe the form $\{V, O\}$ (green) but never the form $\{O, V\}$. Intuitively, for intermediate values of $\eta^{H}$ both the headquarter services and the component inputs matter substantially for the production process. The uniform organizational structures $\{O, O\}$ and $\{V, V\}$ are thus not payoff-maximizing, as they exacerbate the underinvestment problem for the producer or, respectively, for the suppliers to an undue extent. Hybrid sourcing leads to a better balance of these underinvestment problems, and it is then relatively more important to properly incentivize the supplier of the technologically more important component by leaving him the property rights over his assets.

This result represents the standard incentive mechanism known from the property rights literature. According to this result, we would thus expect that firms in practice should outsource their technologically most important inputs while keeping only relatively unimportant components vertically integrated. This theoretical result is at odds with the recent evidence provided discussed in the introduction, see e.g. Corcos et al. (2012), Costinot et al. (2011) or Alfaro and Charlton (2009), which shows that firms in practice often keep their most important inputs vertically integrated.

\section{b) Organization-specific unit costs: direct and indirect impact of the ownership decision}

Now suppose that $\rho^{O}>0$ holds so that outsourcing is associated with higher total unit costs than vertical integration. The producer's ownership decision for this case, which is influenced both by the direct and the indirect impact, is depicted in the right panel of figure 4.

When the headquarter-intensity $\eta^{H}$ is sufficiently high, the producer vertically integrates both suppliers, independently of the technological asymmetry. The reasons are twofold. First, headquarter services are highly important for the production process, thus it is most important to minimize the underinvestment problem for the producer which is achieved by vertical integration. Second, this choice is even reinforced since vertical integration is also associated with lower unit costs than outsourcing. This possibility to exploit economies of scope thus renders the organizational form $\{V, V\}$ more prevalent, i.e., the red area expands in the right panel of figure 4 as compared to the left panel. Also similarly as before, for intermediate values of $\eta^{H}$, we find that the producer chooses "hybrid sourcing” such that she outsources the more important supplier. Specifically, for values of $\eta^{H}$ slightly below $1 / 2$, and for $\eta_{a}$ sufficiently close to the symmetric benchmark we still have $\{0, V\}$ for $\eta_{a}>1 / 2$ and $\{V, O\}$ for $\eta_{a}>1 / 2$. In other words, the standard prediction of the property rights approach that was widespread in the left panel can still prevail in the right panel. However, the parameter range where this happens is now smaller than before, since the producer chooses integration of both suppliers more easily.

Most importantly, the crucial difference between the right and the left panel of figure 4 is visible for low values of the headquarter-intensity. Here, outsourcing of both components is only payoff- 
maximizing if the technological asymmetry across components is small. For sufficiently asymmetric inputs and low headquarter-intensity, we find that the producer now chooses vertical integration of the more important and outsourcing of the less important component. Specifically, for low $\eta^{H}$ we have $\{V, O\}$ if $\eta_{a} \gg 1 / 2$ and $\{O, V\}$ for $\eta_{a} \ll 1 / 2$.

What is the intuition for these results? Recall that without additional outsourcing costs (for $\rho^{O}=0$ ) the ownership choice $\{O, O\}$ is payoff-maximizing for low values of $\eta^{H}$ because of the standard property rights effect. With $\rho^{O}>0$, outsourcing is now associated with higher unit costs. This cost increase does, for an unchanged ownership choice $\{O, O\}$, not affect the revenue shares $\beta_{i}^{\{0,0\}}$, but the suppliers' input provisions decrease as they now face higher unit costs. The firm’s total revenue and payoff decrease. From the firm's perspective, it is most urgent to avoid the cost-driven investment reduction for the important component. The producer thus has an incentive to vertically integrate the respective supplier, in order to give him an effective cost advantage and to boost his incentives. Although the respective supplier then loses his property rights, which per se negatively affects his incentives, this is more than offset by the effect from the relatively lower unit costs.

Put differently, the extra costs of outsourcing per se favor vertical integration of both inputs. At the margin, however, integration is favored more strongly for the supplier of the technologically more important component. The standard property rights mechanism still works in the other direction. When the components are not too different in their technological importance, the producer thus still chooses to outsource both suppliers. Also it is still the case that a transfer of property rights is relatively more profitable for the supplier of the more important component. Yet, when the technological asymmetry is sufficiently strong, the indirect effect via the induced cost asymmetry comes to dominate.

In the right panel of Figure 4 we have assumed a specific value for $\rho^{O}$. When we increase the extra costs of outsourcing even further, the entire figure would eventually turn red. That is, the producer would always choose $\{V, V\}$ is $\rho^{O}$ is high enough. In the transition towards this extreme constellation, the switch from outsourcing to integration occurs later in the far left part of the figure where headquarter-intensity is very low, since the property rights effect has the strongest bite for the suppliers there. It also occurs later for constellations with a small technological asymmetry (for $\eta_{a} \approx 1 / 2$ ), as just explained, since the induced push in investment incentives coming from the lower unit costs is then smaller. ${ }^{13}$

Summing up, our closed economy framework shows that, despite the negative direct impact of the loss of ownership rights on the bargaining power and the investment incentives of suppliers, the producer may still choose to vertically integrate the relatively more important manufacturing component, and to

\footnotetext{
${ }^{13}$ We may also consider a constellation where the extra costs of outsourcing differ across components. For example, suppose that $\rho_{a}^{o}>\rho_{b}^{o}$. This difference may arise, for example, because tighter monitoring or closer interaction with the final assembly department is required for input $a$ which is facilitated by vertical integration. Numerical simulations for the final ownership decision show that the producer would then integrate input $a$ even earlier, compared to a constellation where scope economies are the same for both inputs $\left(\rho_{a}^{O}=\rho_{b}^{O}\right)$.
} 
outsource the relatively less important one, if economies of scope are high enough. The emergence of this empirically highly relevant constellation hinges on the interaction of the direct and the indirect effect of the producer's ownership choice, both of which affect the players' Shapley values and their investment incentives.

\section{Open economy}

We now turn to the open economy setup where the producer decides both on the ownership form of the two suppliers, and on their location $r=\{D, F\}$. As stated above, we assume that foreign manufacturers can produce the component at lower raw unit costs than domestic ones, i.e. $c_{i, D}>c_{i, F}$ for $i=\{a, b\}$. If this were the only cost difference across countries, it is clear from the previous analysis that the producer would then always offshore both components. This would simultaneously decrease unit costs for both suppliers, and hence their investment incentives and the firm's revenue level, while there are no disadvantages of choosing foreign component manufacturing. Moreover, recall that the suppliers' outside opportunities $w_{r}^{M}$ differ across countries, and that the producer adjusts the upfront participation fees $\tau_{i}$ so that suppliers receive an overall payoff that matches their outside opportunity. From the firm's perspective, there are hence fixed agency costs. Supposedly the outside opportunities for suppliers are lower in the foreign low-wage country. The firm would thus have lower agency costs when choosing foreign component manufacturing and this channel would then even reinforce the decision for full offshoring.

However, it is widely known that offshoring not only generates cost advantages for firms from developed countries, but it often leads to higher communication and transportation costs, more expensive managerial oversight, and so on. To take this into account, we introduce an extra fixed cost $f_{X}$ per offshored component, capturing those higher transaction costs for the firm. In particular, let $\Delta=w_{F}^{M}+f_{X}-w_{D}^{M}$. This term captures the difference in total fixed costs when component $i$ is offshored, as compared to domestic manufacturing of that input. We assume that $\Delta>0$, so that the additional costs $f_{X}$ associated with offshoring outweigh the potentially lower outside opportunity in the foreign country.

\subsection{The producer's ownership and global scale decision in the open economy}

Notice from equation (8) that the overall payoff of the firm (which the producer aims to maximize) can be separated into a variable payoff and a fixed cost component. For the producer's global scale decision, we hence have a trade-off: Foreign suppliers have lower unit costs of production. Hence, offshoring tends to raise the variable payoff of the firm. However, the firm's fixed costs are higher when choosing offshoring. More specifically, full offshoring induces higher fixed costs than partial offshoring of only one component, and complete domestic component manufacturing is associated with the lowest fixed costs. 
The variable payoff is magnified by the term $\Theta$ that captures the firm's productivity and market size, whereas the fixed costs are independent of this term. This implies that highly productive firms are more prone to choosing offshoring, since the impact of fixed costs on the total payoff is relatively small. Firms with low productivity choose domestic component manufacturing in order to save fixed costs, even if this is associated with a lower variable payoff level. Figure 5 displays the resulting ownership and location decisions for a given fixed cost difference $\Delta$. On the vertical axis we display the degree of the technological asymmetry $\eta_{a}$, and on the horizontal axis the productivity/market size term $\Theta$. The three panels differ with respect to the headquarter-intensity. In the left panel we assume a high level, in the middle panel an intermediate value, and in the right panel a low value of $\eta^{\mathrm{H}}$. In all cases we abstract from extra costs of outsourcing, i.e., we assume that $\rho_{r}^{O}=\rho_{r}^{V}=0$.

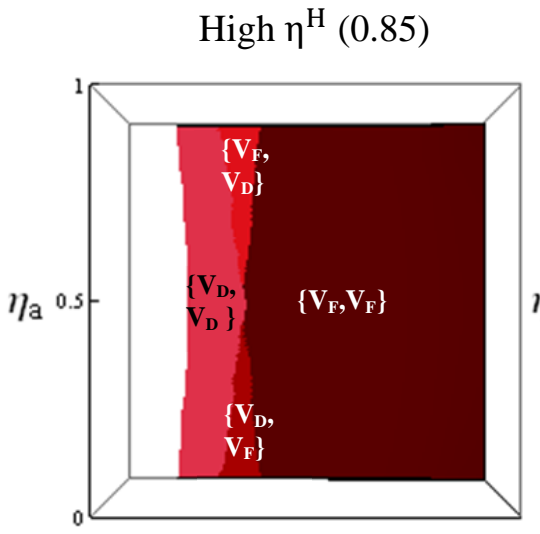

$\Theta$

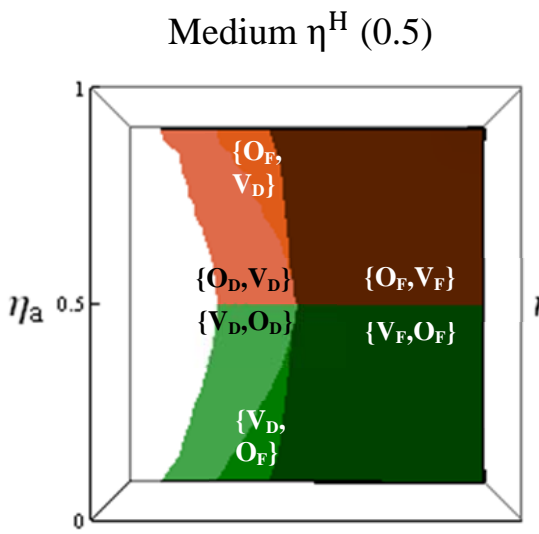

$\Theta$

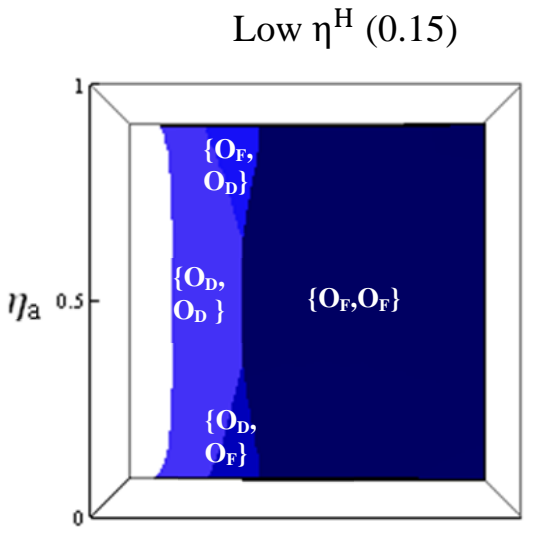

$\Theta$

Figure 5: Organizational decision in the open economy $\left(c_{a, D}=c_{b, D}=1, c_{a, F}=c_{b, F}=0.9, c^{\mathrm{H}}=1, \Delta=10^{-9}, \delta^{0}=1, \delta^{\mathrm{V}}=0.95, \rho^{o}=\rho^{V}=0, \alpha=0.92, \varepsilon=0.06\right)$.

With respect to the ownership decision, the figures show the same pattern as in the closed economy model (see left panel of figure 4). For high headquarter-intensity the producer chooses complete vertical integration (red), for low $\eta^{\mathrm{H}}$ she chooses complete outsourcing (blue) and for intermediate values of $\eta^{\mathrm{H}}$ she chooses hybrid sourcing where, respectively, the supplier of the more important component is outsourced and the other supplier is integrated. This pattern is driven by the direct property rights channel only, since the indirect impact via the ownership-specific unit costs is still absent. The new insight of figure 5 concerns the producer's global scale decision. Here, all three panels have the same ranking in common: Firms with very low productivity/market size are not able to cover fixed costs, not even when choosing domestic input suppliers, and they are hence not operating at all (indicated by the white area). As $\Theta$ rises, firms become able to operate. The global scale decision then changes from a completely domestic organization, to partial offshoring of only one component, to complete offshoring of both components. This is indicated by the successively darker shades of the respective colors in figure 5 .

The smaller the cross-country fixed cost difference $\Delta$ is the more likely is offshoring. This is shown in figure 6 . Here we illustrate the same constellations as in figure 5 , but we hold productivity/market size 
$\Theta$ constant and consider variations of $\Delta$ on the horizontal axis. We find that the ownership decision (outsourcing versus integration) hinges on the firm's headquarter-intensity and on the degree of the technological asymmetry of the two components, while the magnitude of $\Delta$ drives the firm's global scale decision. All three panels have in common that for a low value of $\Delta$ offshoring of both components is chosen. When the offshoring costs $\Delta$ increase, the producer finds it profitable to offshore only the more important supplier (given that the technological asymmetry is sufficiently strong), and for high offshoring costs the payoff is maximized by keeping both suppliers domestic.

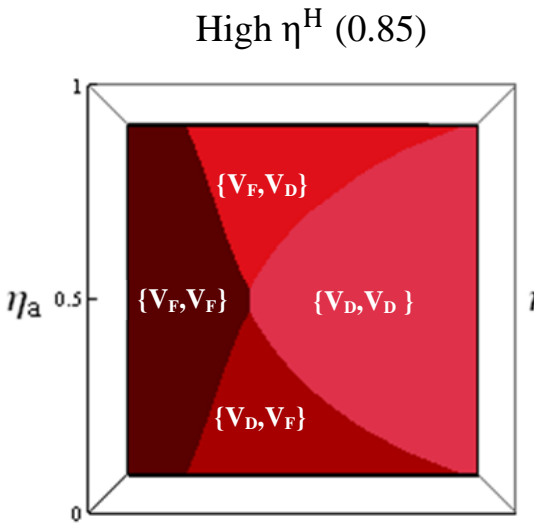

$\Delta$

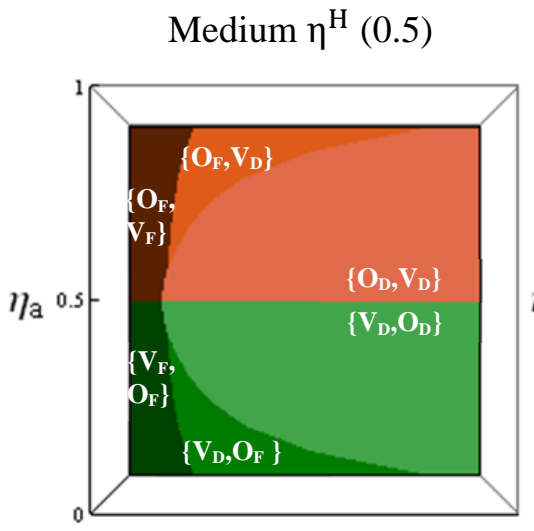

$\Delta$

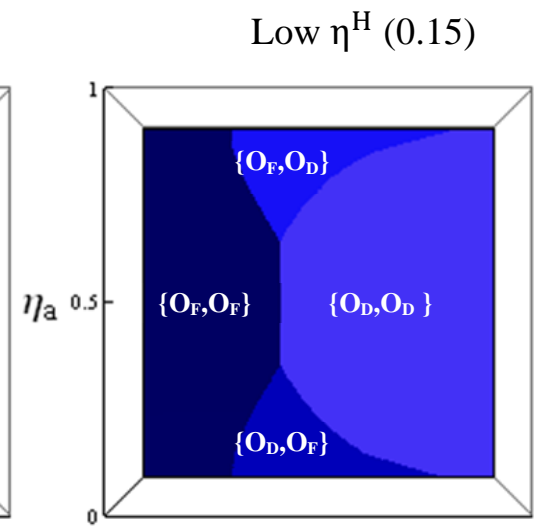

$\Delta$

Figure 6: Organizational decision for different offshoring costs, without economies of scope $\left(c_{a, D}=c_{b, D}=1, c_{a, F}=c_{b, F}=0.9, c^{H}=1, \delta^{0}=1, \delta^{V}=0.95, \rho^{O}=\rho^{V}=0, \alpha=0.92, \varepsilon=0.06, \theta=1, Y=1\right)$.

Notice that in both figures 5 and 6 we have assumed that $\rho^{O}=\rho^{V}=0$. That is, we have assumed that there are no ownership-specific differences in the suppliers' unit costs, and thereby we have shut down the indirect impact of the producer's ownership decision on the suppliers' bargaining powers and incentives. We now re-introduce the extra costs of outsourcing by setting $\rho^{O}>\rho^{V}=0$, but we assume that those additional costs do not differ across countries $\left(\rho_{D}^{O}=\rho_{F}^{O}\right)$. In other words, we assume that economies of scope can be exploited to the same extent both within and across countries.

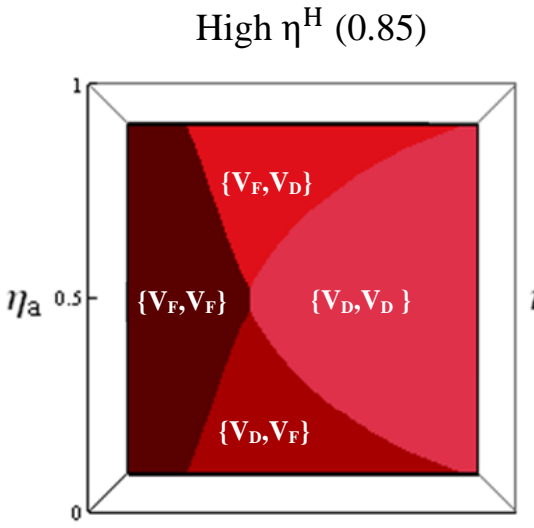

$\Delta$

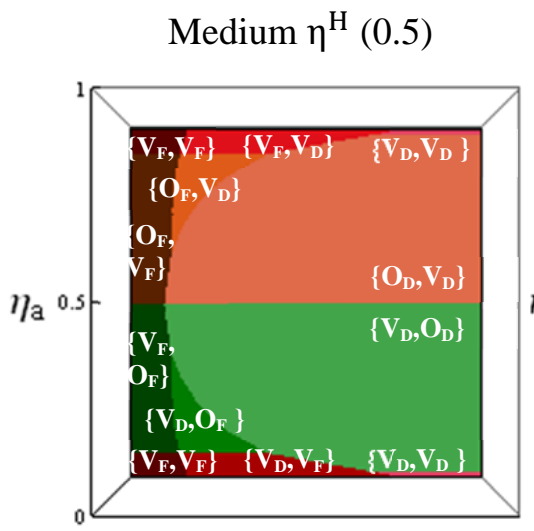

$\Delta$

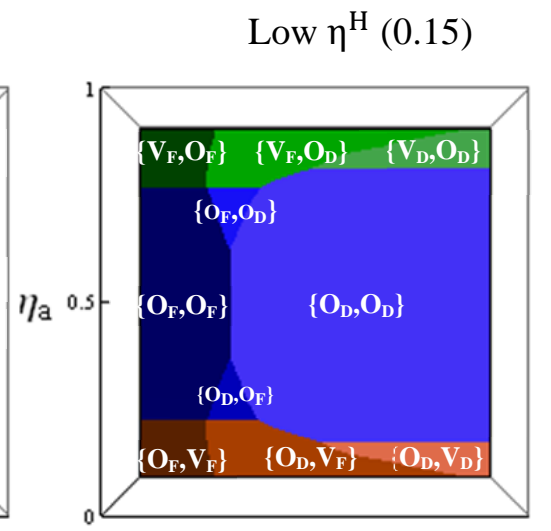

$\Delta$

Figure 7: Organizational decision for different offshoring costs, with economies of scope $\left(c_{a, D}=c_{b, D}=1, c_{a, F}=c_{b, F}=0.9, c^{H}=1, \delta^{0}=1, \delta^{\mathrm{V}}=0.95, \rho^{O}=0.155, \rho^{V}=0, \alpha=0.92, \varepsilon=0.06, \theta=1, Y=1\right)$. 
Figure 7 is analogous to figure 6 and is constructed for a given level of $\Theta$ and for a given value $\rho^{O}>0$. The crucial change occurs in the right panel, i.e., for low headquarter-intensity of final goods production. Without the extra costs of outsourcing, the producer would choose to subcontract both components. When the extra costs of outsourcing matter, however, we find that the producer now decides to vertically integrate the more important component if the technological asymmetry is large enough, as can be seen by the green and the orange areas in figure 7 for very high and very low values of $\eta_{a}$, respectively. This is essentially the same pattern as in figure 4 (right panel) above. Whether this pattern of hybrid sourcing happens in the domestic or in the foreign country is then again determined by the offshoring cost $\Delta$.

\subsection{Country-specific differences in the extra costs of outsourcing}

Finally, we can briefly consider country-specific differences in the extra costs of outsourcing. Specifically, suppose that outsourcing implies a relatively stronger extra cost when conducted abroad, $\rho_{F}^{O}>\rho_{D}^{O}>0$. This may be the case, e.g. because communication with external foreign suppliers is particularly difficult and several adaptions are necessary before the inputs of those suppliers are usable for final goods production. ${ }^{14}$

What this assumption does is to tilt ownership decisions into the direction of intra-firm trade and away from arm's length outsourcing. In particular, when redoing figure 7, we observe in the middle and right panel that the producer now chooses to vertically integrate both components via intra-firm trade more often, in order to avoid the cost-driven reduction of the input provision of the external supplier. If she does not integrate both components, at least she tends to integrate the more important component more easily if the technological asymmetry across components is sufficiently large. In the left panel of figure 7 we would observe no change in the ownership or global scale decision. The producer chooses a fully internal organization of the supplier relationships anyway (either at home or abroad, depending on $\Delta$ ) and this choice is now only reinforced by extra costs of outsourcing.

\section{Conclusion}

We study global sourcing decisions in a property rights model of a multinational firm, where a producer interacts with two potentially technologically asymmetric suppliers. Our model extends the seminal framework by Antràs and Helpman (2004). It allows capturing the empirically highly relevant scenario of "hybrid sourcing" where the firm chooses a different sourcing mode for some suppliers than for others, and in particular, it makes predictions under which conditions the firm chooses to outsource the relatively less important and to vertically integrate the more important input.

In line with the fundamental logic of the property rights approach, a transfer of ownership rights incentivizes suppliers in our framework. According to this "direct" effect, the producer therefore tends

\footnotetext{
${ }^{14}$ Notice that, depending on the magnitude of $\rho_{F}^{O}$, the total unit costs of external foreign suppliers may be higher or lower than the unit costs of internal domestic ones, as raw unit costs are still lower in the foreign country.
} 
to outsource the technologically important input. This pattern is, however, at odds with recent empirical studies which indicate that firms in practice tend to outsource mostly relatively standard and simple tasks, while complex and technologically highly important inputs are often kept inside the firm's boundaries. Therefore we introduce a second, indirect effect of the ownership choice by considering economies of scope, which we formalize as extra costs of outsourcing. Intuitively, when a supplier's ownership status switches from affiliated to external, not only property rights are transferred to the supplier, but there is also an induced unit costs increase as the supplier henceforth lacks of economies of scope. The former aspect stimulates, while the latter aspect dampens the supplier's incentive to produce. Per se, the latter "indirect" channel pushes for vertical integration of both suppliers. Yet, at the margin this effect is stronger for the supplier of the more important input, so that the producer has a stronger incentive for vertical integration of that more important supplier. In an open economy setting we find that the global scale decision depends on the productivity of the firm and the size of the market in which the firm operates. Higher productivity or larger market size make foreign sourcing more likely, as do lower offshoring costs.

Our model could be extended in various directions. First, the model exogenously imposes that there are two input suppliers involved in final-goods production. An interesting question would be how economies of scope influence the endogenous complexity decision of firms, i.e., how thinly multinationals slice up the production process by relying on more and more specialized input suppliers. Recent attempts to explore such questions are provided by Acemoglu et al. (2007) and Schwarz and Suedekum (2011). Second, both inputs are simultaneously combined to a final-goods variety. A recent contribution by Antràs and Chor (2011) focuses on a sequential production chain, where intermediate inputs pass through various stages and are refined in each stage. That model abstracts from technological differences across suppliers on the different stages, however. Third, we focus on a partial equilibrium setup by analyzing the sourcing decision of a single firm. However, general equilibrium effects might also reveal new insights on the question why firms choose different sourcing modes for different inputs. Exploring those and other extensions is left for future research.

\section{References}

Acemoglu, D., P. Antràs and E. Helpman (2007) Contracts and Technology Adaption, American Economic Review 97(3), 916-943.

Aghion, P. and J. Tirole (1997) Formal and Real Authority in Organizations, Journal of Political Economy 105(1), 1-29.

Agrawal, P. (2002) Double Moral Hazard, Monitoring, and the Nature of Contracts, Journal of Economics 75(1), 33-61.

Alchian, A.A. and H. Demsetz (1972) Production, Information Costs, and Economic Organization, American Economic Review 62(5), 777-795.

Alfaro, L. and A. Charlton (2009) Intra-Industry Foreign Direct Investment, American Economic Review 99(5), 2096-2119. 
Antràs, P. (2012) Grossman-Hart (1986) Goes Global: Incomplete Contracts, Property Rights, and the International Organization of Production, unpublished manuscript, Harvard University.

Antràs, P. and D. Chor (2011) Organizing the Global Value Chain, unpublished manuscript, Harvard University.

Antràs, P. and E. Helpman (2004) Global Sourcing, Journal of Political Economy 112(3), 552-580.

Antràs, P. and E. Helpman (2008) Contractual Frictions and Global Sourcing. In: Helpman, E., D. Marin, and T. Verdier (eds.) The Organization of Firms in a Global Economy, Harvard University Press, 9-54.

Antràs, P. and E. Rossi-Hansberg (2009) Organizations and Trade, Annual Review of Economics 1, 43-64.

Arya, A., B. Mittendorf and D.E.M. Sappington (2008) The Make-or-Buy Decision in the Presence of a Rival: Strategic Outsourcing to a Common Supplier, Management Science 54(10), 1747-1758.

Bae, S.H., C.S. Yoo and J. Sarkis (2010) Outsourcing with Quality Competition: Insights from a Three Stage Game Theoretic Model, International Journal of Production Research 48(2), 327-342.

Bajari, P. and S. Tadelis (2001) Incentives versus Transaction Costs: a Theory of Procurement Contracts, RAND Journal of Economics 32(3), 387-407.

Bengtsson, L., R. von Haartman and M. Dabhilkar (2009) Low-Cost versus Innovation: Contrasting Outsourcing and Integration Strategies in Manufacturing, Creativity and Innovation Management 18(1), 35-47.

Bental, B., B. Deffains and D. Demougin (2012) Credibility and Monitoring: Outsourcing as a Commitment Device, Journal of Economics \& Management Strategy 21(1), 31-52.

Bernard, A.B., J.B. Jensen, S.J. Redding and P.K. Schott (2010) Intrafirm Trade and Product Contractibility, American Economic Review 100(2), 444-448.

Carluccio, J. and T. Fally (2012) Global Sourcing under Imperfect Capital Markets, forthcoming: Review of Economics and Statistics.

Chesbrough, H.W. and D.J. Teece (1996) When Is Virtual Virtuous? - Organizing for Innovation, Harvard Business Review, January-February, 65-73.

Coase, R. (1937) The Nature of the Firm, Economica 4(16), 386-405.

Corcos, G., D.M. Irac, G. Mion and T. Verdier (2012) The Determinants of Intra-Firm Trade, forthcoming: Review of Economics and Statistics.

Costinot, A., L. Oldenski and J. Rauch (2011) Adaptation and the Boundary of Multinational Firms, Review of Economics and Statistics 93(1), 298-308.

Crémer, J., L. Garicano and A. Prat (2007) Language and the Theory of the Firm, Quarterly Journal of Economics 122(1), 373-407.

Defever, F. and F. Toubal (2011) Productivity, Relationship-Specific Inputs and the Sourcing Modes of Multinational Firms, CEPR Discussion Papers No. 8656. 
Du, J., Y. Lu and Z. Tao (2009) Bi-Sourcing in the Global Economy, Journal of International Economics 77(2), 215-222.

Dunning, J.H. (1977) Trade, Location of Economic Activity and the MNE: A Search for an Eclectic Approach. In: Ohlin, B., P.-O. Hesselborn and P.M. Wijkman (eds.) The International Allocation of Economic Activity: Proceedings of a Nobel Symposium Held at Stockholm, Macmillan, 183-218.

Ethier, W.J. (1986) The Multinational Firm, Quarterly Journal of Economics 101(4), 805-833.

Ethier, W.J. and J.R. Markusen (1996) Multinational Firms, Technology Diffusion and Trade, Journal of International Economics 41, 1-28.

Federico, S. (2010) Outsourcing versus Integration at Home or Abroad, Empirica 37(1), 47-63.

Grossman, S. and O. Hart (1986) The Costs and Benefits of Ownership: A Theory of Vertical and Lateral Integration, Journal of Political Economy 94(4), 691-719.

Grossman, G.M. and E. Helpman (2004) Managerial Incentives and the International Organization of Production, Journal of International Economics 63, 237-262.

Hart, S. (1990) Advances in Value Theory. In: Ichiishi, T., A. Neyman, and Y. Tauman (eds.) Game Theory and Applications, Academic Press, 166-175.

Hart, S. and A. Mas-Colell (1988) The Potential of the Shapley Value. In: Roth, A.E. (ed.) The Shapley Value, Cambridge University Press, 127-137.

Hart, O. and J. Moore (1990) Property Rights and the Nature of the Firm, Journal of Political Economy 98(6), 1119-1158.

Holmström, B. and P. Milgrom (1991) Multitask Principal-Agent Analyses: Incentive Contracts, Asset Ownership, and Job Design, Journal of Law, Economics, \& Organization 7, Special Issue, 24-52.

Jabbour, L. (2008) Slicing the Value Chain Internationally: Empirical Evidence on the Offshoring Strategy by French Firms, GEP Research Paper 2008/02.

Jabbour, L. and R. Kneller (2010) Multiple Offshoring: Evidence for French Firms, unpublished manuscript, University of Nottingham.

Keuschnigg, C. and M.P. Devereux (2009) The Distorting Arm's Length Principle, CEPR Discussion Paper No. 7375.

Kohler, W. and M. Smolka (2012) Global Sourcing Decisions and Firm Productivity: Evidence from Spain. Forthcoming in: Stern, R.M. (ed.) Quantitative Analysis of Newly Evolving Patterns of International Trade: Fragmentation, Offshoring of Activities, and Vertical Intra-Industry Trade, World Scientific Studies in International Economics.

Lakemond, N., C. Berggren and A. van Weele (2006) Coordinating Supplier Involvement in Product Development Projects: A Differentiated Coordination Typology, R\&D Management 36(1), 55-66.

Li, Z. (2009) Task Offshoring and Organizational Form: Theory and Evidence from China, Working Paper 101, FREIT.

Lu, Y., T. Ng and Z. Tao (2012) Outsourcing, Product Quality, and Contract Enforcement, Journal of Economics \& Management Strategy 21(1), 1-30. 
Marin, D. and T. Verdier (2008) Power Inside the Firm and the Market: A General Equilibrium Approach, Journal of the European Economic Association 6(4), 752-788.

Marin, D. and T. Verdier (2012) Globalization and the Empowerment of Talent, Journal of International Economics 86(2), 209-223.

Markusen, J.R. (1995) The Boundaries of Multinational Enterprises and the Theory of International Trade, Journal of Economic Perspectives 9(2), 169-189.

Naghavi, A., J. Spies and F. Toubal (2011) International Sourcing, Product Complexity and Intellectual Property Rights, Working Paper 2011.78, Fondazione Eni Enrico Mattei.

Novak, S. and B. Wernerfelt (2012) On the Grouping of Tasks into Firms: Make-or-Buy with Interdependent Parts, Journal of Economics \& Management Strategy, 21(1), 53-77.

Nunn, N. and D. Trefler (2008) The Boundaries of the Multinational Firm: An Empirical Analysis. In: Helpman, E., D. Marin, and T. Verdier (eds.) The Organization of Firms in a Global Economy, Harvard University Press, 55-83.

Rugman, A.M. (1986) New Theories of the Multinational Enterprise: An Assessment of Internalization Theory, Bulletin of Economic Research 38(2), 101-118.

Schwarz, C. and J. Suedekum (2011) Global Sourcing of Complex Production Processes, CESifo Working Paper Series No. 3559.

Shapley, L. (1953) A Value for n-Person Games. In: Kuhn, H.W. (ed.) Classics in Game Theory, Princeton University Press, 69-79.

Tadelis, S. (2002) Complexity, Flexibility, and the Make-or-Buy Decision, American Economic Review 92(2), 433-437.

Tomiura, E. (2007) Foreign Outsourcing, Exporting, and FDI: A Productivity Comparison at the Firm Level, Journal of International Economics 72(1), 113-127.

Ulrich, K.T. and D.J. Ellison (2005) Beyond Make-Buy: Internalization and Integration of Design and Production, Production and Operations Management 14(3), 315-330.

Williamson, O.E. (1975) Markets and Hierarchies: Analysis and Antitrust Implications. New York: Free Press.

Williamson, O.E. (1985) The Economic Institutions of Capitalism. New York: Free Press.

Zeiteisen (2011a) Interview mit Jerome Lambert, CEO von Jaeger-LeCoultre.

URL: http://www.zeiteisen.at/blog/page12.html.

Zeiteisen (2011b) Interview mit Dieter Pachner, Glashütte Original.

URL: http://www.zeiteisen.at/blog/page12.html. 


\section{Appendix}

In the main text we have formalized the notion of scope economies as "extra costs of outsourcing" which are borne by the suppliers. In this appendix, we analyze an alternative formalization where the producer faces higher costs when choosing an external supplier organization. This modeling may correspond more closely to some of the mechanisms discussed in section 2. Formally, we now study a five stage game where stages 1-3 are identical to those discussed in the main text. Stages 4 and 5 change as follows:

4b) The headquarter and the suppliers $a$ and $b$ decide independently on their noncontractible input provision levels ( $h$ and, respectively, $m_{a}$ and $m_{b}$ ). The unit costs of production for input $i \in\{a, b\}$ are given by $c_{i, r}$ and are independent of the supplier's organizational form. The unit costs of headquarter services are given by $c^{H}$.

5b) The three players bargain over the surplus value of the relationship. Before the final good can be produced, the producer must pay a cost $\rho_{a}^{\Xi_{a}} \cdot m_{a}+\rho_{b}^{\Xi_{b}} \cdot m_{b}$, where $\rho_{i, r}^{O} \geq \rho_{i, r}^{V}$ for $i \in\{a, b\}$, otherwise output is zero. Revenue is realized and distributed according to the outcome of the bargaining process.

The most natural interpretation of this alternative modeling approach is that component inputs must be adapted ex post by the producer, after the input investments of all agents are sunk and the bargaining is completed. The adaption costs per unit are higher for inputs delivered by external suppliers, e.g. because there is less ex ante control. ${ }^{15}$

With this formalization, suppliers maximize $\beta_{i} \cdot R-c_{i}^{M} \cdot m_{i}$ in the fourth stage of the game. The producer maximizes $\beta^{H} \cdot R-c^{H} \cdot h$, since she takes $m_{a}$ and $m_{b}$ as given in stage 4 . The individually payoff-maximizing input provisions are thus

$$
h=\frac{\alpha \cdot \eta^{H} \cdot \beta^{H}}{c^{H}} \cdot R \quad \text { and } \quad m_{i}=\alpha \cdot\left(1-\eta^{H}\right) \cdot \eta_{i} \cdot \frac{\left(\frac{\beta_{i}}{c_{i, r}}\right)^{\frac{1}{1-\varepsilon}}}{\eta_{a} \cdot\left(\frac{\beta_{a}}{c_{a, r}}\right)^{\frac{\varepsilon}{1-\varepsilon}}+\eta_{b} \cdot\left(\frac{\beta_{b}}{c_{b, r}}\right)^{\frac{\varepsilon}{1-\varepsilon}}} \cdot R
$$

with total revenue given by

$$
R=\Theta \cdot\left[\left(\frac{\beta^{H}}{c^{H}}\right)^{\eta^{H}} \cdot\left(\eta_{a} \cdot\left(\frac{\beta_{a}}{c_{a, r}}\right)^{\frac{\varepsilon}{1-\varepsilon}}+\eta_{b} \cdot\left(\frac{\beta_{b}}{c_{b, r}}\right)^{\frac{\varepsilon}{1-\varepsilon}}\right)^{\left(\frac{1-\varepsilon}{\varepsilon}\right) \cdot\left(1-\eta^{H}\right)}\right]^{\frac{\alpha}{1-\alpha}}
$$

Since $h, m_{a}, m_{b}$ and $R$ are all independent of $\rho_{i, r}^{\Xi_{i}}$, there is hence no impact of this organizationspecific cost term on the agents' Shapley values or their investment incentives. In stage 1 , the producer eventually aims at maximizing the joint payoff of the relationship:

\footnotetext{
${ }^{15}$ The formalization in the main text corresponds to the other extreme, where suppliers take into account all necessary adaptions ex ante, before input investments are sunk and before entering the bargaining stage.
} 


$$
\pi=R-c^{H} \cdot h-c_{a, r} \cdot m_{a}-c_{b, r} \cdot m_{b}-\left(\rho_{a, r}^{\Xi_{a}} \cdot m_{a}+\rho_{b, r}^{\Xi_{b}} \cdot m_{b}\right)-\left(w_{a}^{r}+w_{b}^{r}\right) .
$$

The term $\left(\rho_{a, r}^{\Xi_{a}} \cdot m_{a}+\rho_{b, r}^{\Xi_{b}} \cdot m_{b}\right)$ thus enters the joint payoff $\pi$ essentially like a fixed cost. Conditional on the level of input provision, this fixed cost is higher for outsourcing than for vertical integration. It is important to note, however, that the magnitude of this fixed cost is larger the higher are the input levels $m_{a}$ and $m_{b}$.

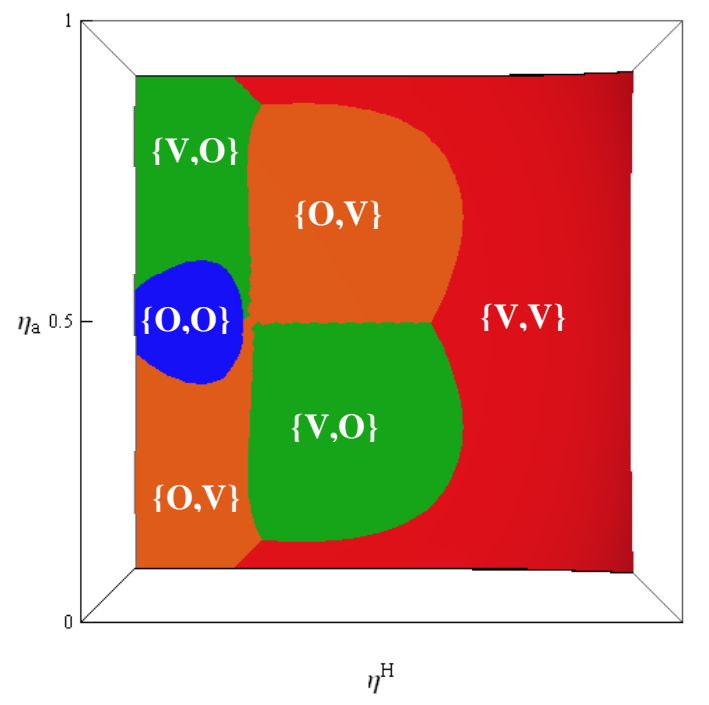

Figure 8: Final ownership decision in the closed economy $\left(c_{a}=c_{b}=1, c^{\mathrm{H}}=1, \delta^{o}=1, \delta^{V}=0.95, \rho^{o}=2.1, \rho^{V}=0, \alpha=0.92, \varepsilon=0.06, \theta=1, Y=1\right)$.

Figure 8 illustrates the producer's final organizational choice for the case with $\rho^{O}>0$ and $\rho^{V}=0$. The pattern is qualitatively similar as in the right panel of figure $4 .^{16}$

To grasp the intuition, focus on a constellation where $\eta^{H}$ is low and where $\eta_{a} \gg 1 / 2$. The producer chooses $\{V, O\}$ in that case. The reason is the following: Since input $a$ is highly important, the input provision $m_{a}$ is large. This, in turn, raises the ex post adaption costs which are increasing in $m_{i}$ for the case of outsourcing. Vertically integrating supplier $a$ negatively affects his incentives due to the loss of ownership rights, but from the firm's perspective this is more than offset by the lower ex post adaption costs. Put differently, this formalization of scope economies per se also favors vertical integration of both inputs. Yet, at the margin the effect is again stronger for the supplier of the more important component, since that supplier delivers a higher input contribution. Notice that this would not be the case if fixed costs were independent of the suppliers input provision levels. In such a case, the firm has no incentive at the margin to vertically integrate the more important component.

Although the producer's final organizational decision is qualitatively similar for both formulations of the extra costs of outsourcing, there is a noteworthy difference. Namely, in the appendix formulation the ownership form of supplier $i$ affects his investment incentives and bargaining power only via the direct ownership rights effect. Specifically, switching from $\Xi_{i}=O$ to $\Xi_{i}=V$ unambiguously lowers

\footnotetext{
${ }^{16}$ When setting $\rho^{O}=\rho^{V}=0$ we would obtain the same pattern as in the left panel of figure 4 .
} 
supplier $i$ 's incentives while the benefit of this switch is the reduction of the firm's ex post adaption costs. In the baseline formulation from the main text, on the other hand, there is no ex post cost reduction for the firm but instead a (positive) indirect effect on supplier $i$ 's incentives when switching from $\Xi_{i}=O$ to $\Xi_{i}=V$. We may compare the two formulations from a quantitative point of view. In figure 9 we assume a low value of $\eta^{H}$ and a high value of $\eta_{a} \gg 1 / 2$, and depict the joint payoff for the baseline case $\left(\pi_{\left\{\Xi_{a}, \Xi_{b}\right\}}^{B F}\right.$, grey lines) and for the appendix formulation ( $\pi_{\left\{\Xi_{a}, \Xi_{b}\right\}}^{A F}$, black lines), respectively. In the absence of economies of scope (for $\rho^{O}=0$ ), the two formulations are equivalent and the producer chooses to outsource both suppliers. For a sufficiently high $\rho^{O}$ she would, in both formulations, choose to integrate the more important component $a$ and to outsource the less important component $b$.

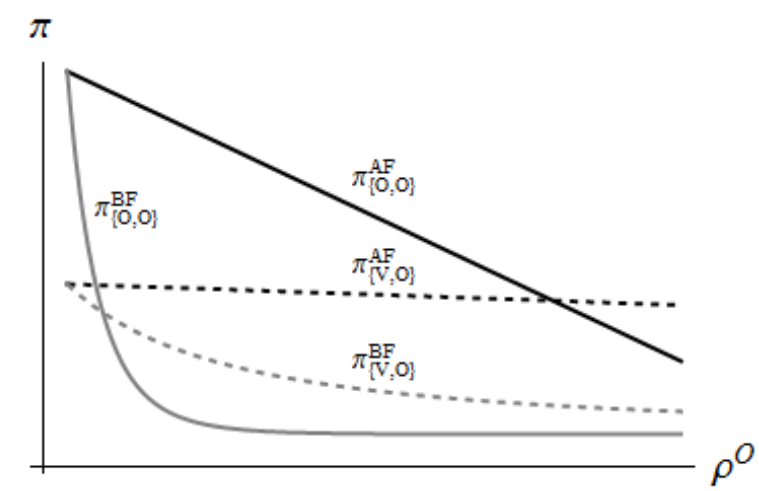

Figure 9: Joint payoff subject to a variation of scope economies $\rho^{O}$ $\left(\eta_{a}=0.8, \eta_{b}=0.2, \eta^{H}=0.3, c_{a}=c_{b}=1, c^{\mathrm{H}}=1, \delta^{O}=1, \delta^{V}=0.95, \alpha=0.92, \varepsilon=0.06, \theta=1, Y=1\right)$.

Yet, figure 9 shows that this switch from $\{O, O\}$ to $\{V, O\}$ occurs on a lower level of $\rho^{O}$ in the baseline formulation than in the appendix formulation (the crossing point of the solid and the broken line is earlier for the grey than for the black curves). Our model thus predicts that the empirically relevant pattern $\{V, O\}$ emerges earlier (for lower $\rho^{O}$ ) when economies of scope affect the suppliers' incentives and not only the firm's overall payoff. 